Article

\title{
High Step-Up 3-Phase Rectifier with Fly-Back Cells and Switched Capacitors for Small-Scaled Wind Generation Systems
}

\author{
Yi-Feng Wang ${ }^{1, \dagger}$, Liang Yang ${ }^{1, *}$, Cheng-Shan Wang ${ }^{1, \dagger}$, Wei Li ${ }^{1}$, Wei Qie ${ }^{2}$ and Shi-Jie Tu ${ }^{3}$ \\ 1 School of Electrical Engineering and Automation, Tianjin University, Tianjin 300072, China; \\ E-Mails: wayif@tju.edu.cn (Y.-F.W.); cswang@tju.edu.cn (C.-S.W.); liwei_19900301@163.com (W.L.) \\ 2 State Grid Tianjin Electric Power Company, Tianjin 300072, China; E-Mail: tjqiewei@126.com \\ 3 State Grid Jiangxi Electric Power Company Repair Branch, Jiangxi 330000, China; \\ E-Mail: nctushijie@126.com
}

$\dagger$ These authors contributed equally to this work.

* Author to whom correspondence should be addressed; E-Mail: zyangliang@tju.edu.cn; Tel./Fax: +86-22-2740-1479.

Academic Editor: Frede Blaabjerg

Received: 26 November 2014 / Accepted: 1 April 2015 / Published: 10 April 2015

\begin{abstract}
This paper proposes and discusses a novel AC/DC converter suitable for small-scaled wind power generation system applications. By introducing flyback cells into the three-phase single-switch Boost circuit, the proposed converter is designed as single-stage and has both rectification and high step-up power conversion functions. It is able to obtain high voltage gain at low input voltage level, and high efficiency, low total harmonic distortion (THD) at rated power. The inherent power factor correction (PFC) is also determined, and can reach 0.99. Besides, since no electrolytic capacitor is employed and high voltage gain is achieved, the converter can also collect weak power at low input voltage in combination with energy storage devices, and contribute to a better low-wind-speed/low-power performance. Finally, a $400 \mathrm{~W}$ prototype is built to verify the theoretical analysis, and its efficiency is $87.6 \%$, while THD is $7.4 \%$ at rated power.
\end{abstract}

Keywords: high step-up; three-phase AC/DC converter; rectifier; flyback; switched capacitor 


\section{Introduction}

In face of the serious energy and environmental pollution crisis, lots of researchers have looked to renewable sources to find solutions. Wind power generation, as an indispensable part of the energy mix, has already shown its competitiveness and reliability to governments, electricity producers and customers all around the world. The rapid growth of the wind generation is surprising: 17.6 GW of wind capacity was installed in the first half of 2014, and the cumulative worldwide wind power capacity is expected to reach $360 \mathrm{GW}$ by end of 2014. The prospects for wind power investment remain positive [1]. Wind generation systems (WGS) containing power electronics devices are often adopted to guarantee high quality electric power supply. Various power electronics converters applied for wind generation have been reviewed and compared in [2]. Most of them are applied for medium and large power levels and few focus their attention on low power level wind power generation, although small-scale wind power generation systems (e.g., under $1 \mathrm{~kW}$ ) are commonly used on domestic roofs in power-hungry areas, including mountainous or insular regions. Thus, more research on distributed, small-scale wind application should be conducted. A considerable number of the existing small-scale WGS still simply copy the structures, designs and control methods for medium- and large-scale WGS, and are unable to meet the practical requirements of the smaller scale scenarios.

Compared to large-scale power level wind generation, small-scale WGS possesses advantages of higher flexibility for distributed applications, lower cost and reduced impact on the power grid, thus further research on this topic and its promotion are of great value.

Usually, small-scaled WGS can be classified into two application forms: off-grid and grid-tied. Off-grid wind generation systems [3-6] are one available form for small-scale wind applications. An off-grid system usually includes a wind generator, a three-phase AC/DC rectifier, a DC/DC Buck converter and the load, as shown in Figure 1.

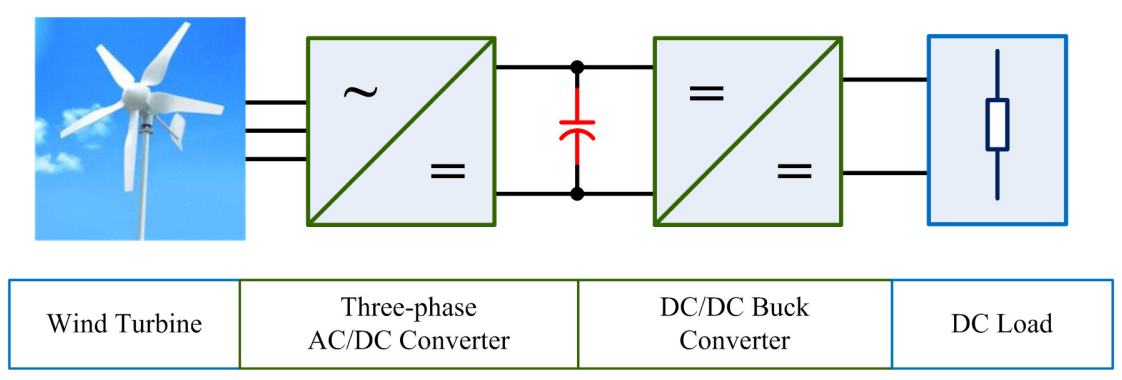

Figure 1. Block diagram of the off-grid wind generation system.

After rectification by the AC/DC circuit, the collected wind energy is further regulated by the Buck converter and delivered directly to the DC load. In [3], a converter for off-grid usage is proposed. By the combination of a three-phase diode bridge rectifier and an interleaved Buck converter, wind energy is converted to the load as power supply. The converter also realizes soft switching for the power switches, which can bring about higher conversion efficiency. Besides, for the general case, the load voltage level always remains low in off-grid WGS, therefore no particular requirements for the DC-link voltage level are needed. Instead, only a simple match for the voltage levels of wind generator, DC-link and the load is required. Thus, the off-grid WGS is relatively easy to realize. However, its applications are limited, because generally, off-grid systems are only suitable for special 
loads with a narrow voltage/power range. Conversely, as a more extensive application form, grid-tied WGS are often made up of a wind generator, a three-phase AC/DC rectifier, a DC/DC converter, an inverter and the grid, as shown in Figure 2.

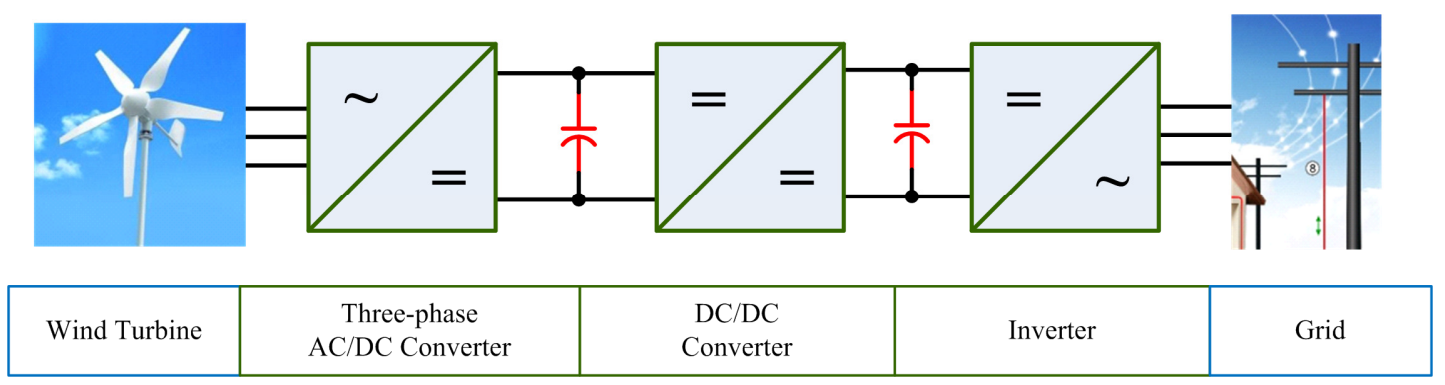

Figure 2. Traditional structure of small-scaled grid-tie wind generation system.

Due to the changeable amplitude and frequency, the alternating electric power generated by the generally adopted permanent magnet synchronous machine (PMSM) must be converted into DC power form first, where the low-cost solution of the three-phase diode bridge rectifier is often used. Then, the DC power is further inverted to AC power again and delivered into the grid. The DC-link voltage should be designed to be higher than the grid voltage to fulfill grid-tie generation [2]. Unfortunately, in small-scale wind fields, the low average and large fluctuation of wind speed will result in rapid fluctuations and low output voltage of the wind generator. The output voltage provided by existing $\mathrm{AC} / \mathrm{DC}$ converters using the maximum power point tracking (MPPT) control strategy is also very low and cannot match up with the required DC-link voltage level for the post-stage grid-tie inverter. Besides, the disability of the power converters to obtain adequate voltage gain at low input voltage, the disability of collecting weak wind energy, and the rigid requirements of the inverters for grid-tie generation also hinder its normal operation. Accordingly, for most existing small-scale WGS it is hard to realize a well-performed grid-tie wind power generation. Several topologies for small-scale WGS have been already researched and compared, as presented in [7-23]. A classical small-scale grid-tie WGS topology, consisting of diode bridge rectifier, DC/DC boost converter and grid-tie inverter is analyzed in [7-9] and shown in Figure 3. This topology possesses advantages like a simple structure, low cost and easy control. In [7], a converter consisting of wind turbine, PMSM generator, three-phase diode rectifier, boost DC/DC circuit, inverter and an LCL filter is analyzed, and can basically realize the wind power delivery. However, the promotion of this converter is limited. On the one hand, although the $\mathrm{DC} / \mathrm{DC}$ boost circuit can provide a high voltage gain, it has drawbacks like high power losses and reduction in reliability. On the other hand, the three-phase diode bridge rectifier is a cost-efficient alternative for small-scaled wind generation, due to its low cost and simple configuration, but it still suffers from high power losses, caused by larger input current, and low power factor, which will introduce rich harmonics and may give rise to vibration, large noise and power resonance [10-12].

To overcome these problems, the back-to-back three-phase pulse width modulation (PWM) converter, as the most frequently used three-phase power converter topology so far in wind turbine systems, was developed [2]. In [13,14], the back-to-back PWM power conversion configuration is chosen and analyzed, as presented in Figure 4. The PWM converter substitutes the diode devices by full controlled switches in both generator side and grid side, and decouples the two sides by a bulky 
DC-link capacitor. It achieves bidirectional power delivery and has a wide power range of applications, from $\mathrm{kW}$ to MW by adopting different levels of power devices. The PWM converter can also obtain outstanding performances of high efficiency, unity power factor and high reliability, but in view of the complicated control strategy and higher cost, which is an important factor of the design purpose, the PWM converter is not the optimal alternative for small-scale WGS $[15,16]$.

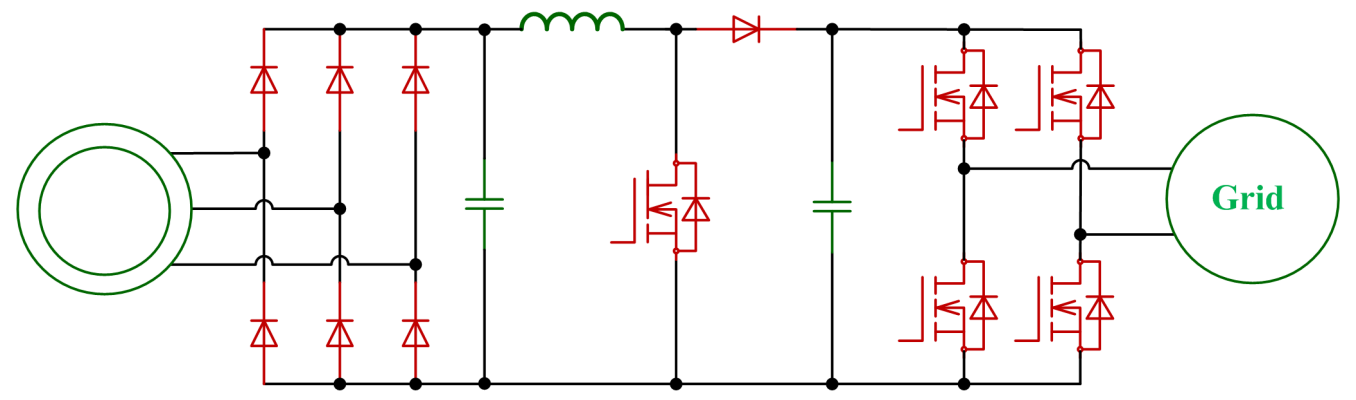

Figure 3. Diode bridge + boost converter wind generation system.

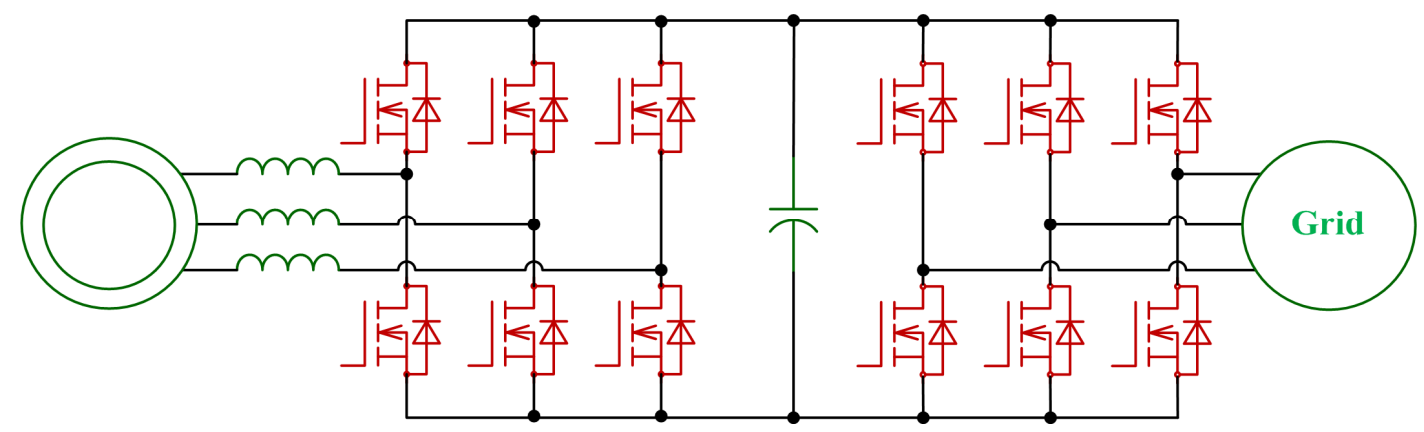

Figure 4. The PWM converter wind generation system.

In $[17,18]$, matrix converters are proposed and analyzed for small-scale WGS as shown in Figure 5. It is made up of full controlled switches with no passive components, and can adjust its current and voltage waveforms by controlling the switching signals [14]. The matrix converter system can realize bidirectional power delivery, controllable current/voltage/power factor and is free of electrolytic capacitor. However, its high cost, intricate control strategy and lack of decoupling between the input and output make it less competitive when applied in small-scale WGS.

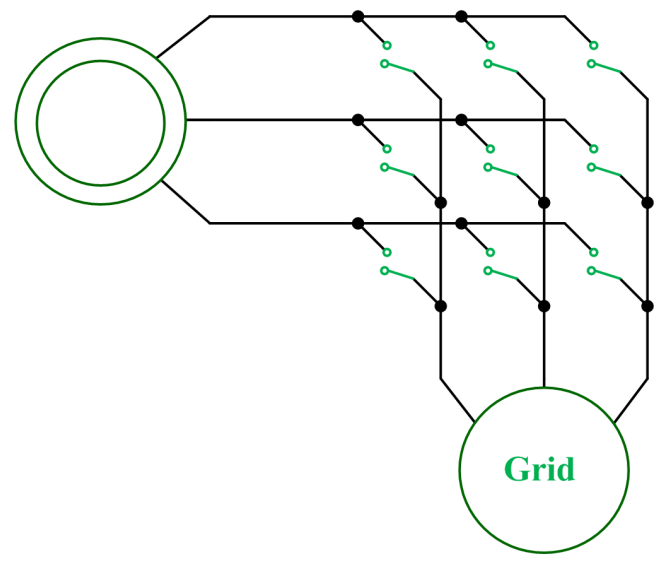

Figure 5. The matrix converter wind generation system. 
To take the performance and the cost into consideration comprehensively, a WGS described in $[19,20]$ adopts the three-phase single-switch boost converter and an inverter as shown in Figure 6. In [20], with only one power switch, the proposed converter possesses the advantages of all three aforementioned converters, including straightforward topology, simple control method, relatively high power factor and efficiency. Thus, it is suitable for small-scale WGS applications [19-22].

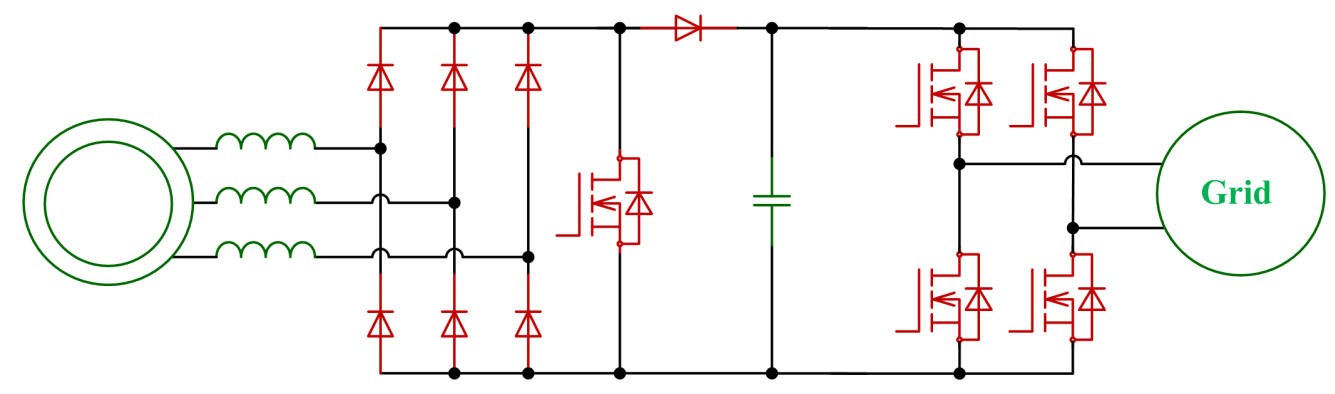

Figure 6. The three-phase single-switch boost converter wind generation system.

Nevertheless, few of these converters can provide a high enough voltage gain and perform a well-functioned grid-tie wind power generation, because of the low average wind speed in small-scale wind fields.

Trying to deal with the DC-link voltage level issue, a boost grid-tie inverter is simulated and tested in [23], where the voltage gain is shared between both the rectifier and the proposed inverter. Grid-tie generation can be realized even when the DC-link voltage is lower than the grid voltage. However, in this topology, high power losses and high current stresses may occur, because of the large ripples in the input inductor currents and the bulky output filter.

Owing to all these problems that exist in the boost inverter, many researches on high step-up DC/DC converters have been developed. Currently, efficient technologies including coupled inductor [24-28] and switched capacitor [25,26,29-33] are often adopted to improve the voltage conversion ratio.

In [24-27], the proposed flyback converter is able to build an additional energy transmission circuit by means of coupled inductors, and can superimpose the output voltage of the additional circuit on that of the main circuit as shown in Figure 7.

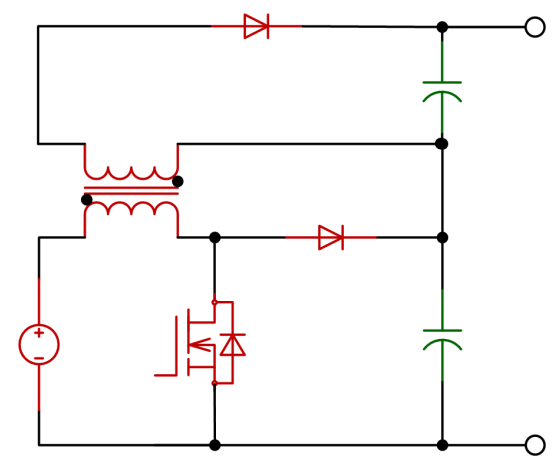

Figure 7. The circuit topology of flyback DC/DC converter.

Thus, a relatively high voltage gain can be achieved. This proposed converter is very suitable for high frequency, low power and high step-up voltage gain applications, but it is usually applied in DC/DC 
cases and needs a cascaded front-stage rectifier to convert the input AC voltage into DC, which may lead to larger losses, lower efficiency and higher cost.

Switched capacitors are also employed frequently in the proposed converters in [29-33]. In Figure 8, as energy snubbers, switched capacitors are able to store and deliver energy from the input source to the output load during one switching cycle, and therefore fulfill high step-up voltage conversion. This technology is widely adopted in many cases, for its light weight and high power density, but its utilization is also generally restrained in DC/DC areas.

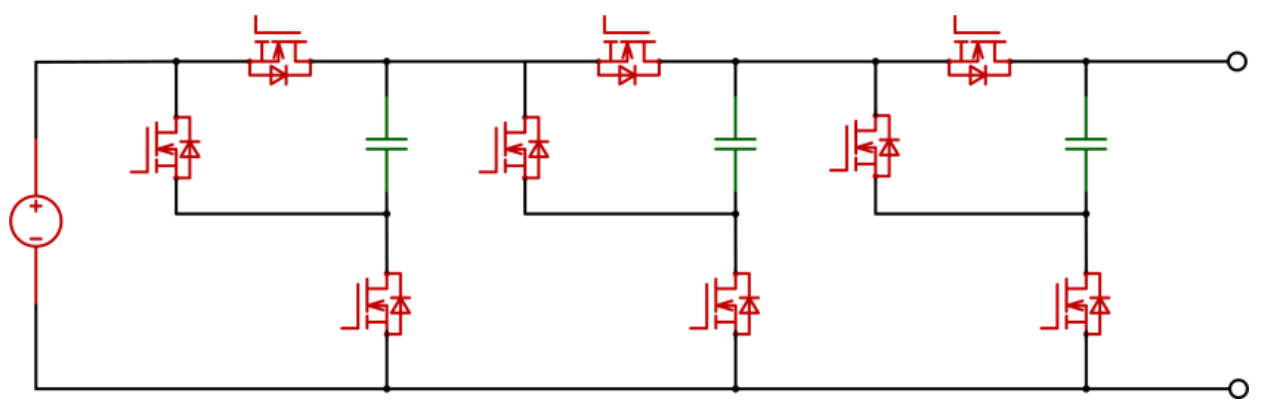

Figure 8. The circuit topology of switched-capacitor DC/DC converter.

Consequently, in order to solve the problems existing in small-scale WGS, in this paper, a novel three-phase high step-up single stage flyback AC/DC converter with switched capacitors is presented and analyzed. The proposed converter is suitable for urban-roof or power-hungry usage scenarios, and can obtain high voltage gain at low input voltage and high power factor, high efficiency in rated situations. Since it has both rectification and voltage gain improvement functions, no additional $\mathrm{DC} / \mathrm{DC}$ converter is needed any longer. The input current is designed to be operated in discontinuous current mode (DCM), and inherent power factor correction (PFC) is also achieved at full load. In addition, no electrolytic capacitor is employed, thus the proposed converter can also collect weak power and has a reduced volume.

\section{Circuit Configuration}

The topology of the proposed converter is presented in Figure 9. By integrating the three-phase single-switch boost circuit and flyback circuits with switched capacitors, the converter can obtain a high voltage gain at low input voltage. The converter is totally divided into four main parts including high frequency filter capacitors $C_{\mathrm{f}}$, uncontrolled diode bridge rectifier $D_{1} \sim D_{6}$, flyback cells and a boost cell ( $L_{\mathrm{ks}}, S_{1}, D_{\mathrm{o}}$ and $C_{\mathrm{o}}$ ). Moreover, for the purpose of tracking the maximum wind power, a variable step size algorithm is adopted [34,35]. The control strategy will be analyzed in detail in further work, and this paper mainly focuses on the topology of the proposed converter.

The diode bridge will rectify the input AC current to DC at first, and then the boost cell is able to boost the rectified voltage as the output voltage of boost cell $V_{\mathrm{M}}$. In flyback cells, since each unit is completely symmetrical, we take phase A for example to explain the configuration of the cells. In phase $\mathrm{A}$, the flyback cell is composed of transformer $T_{1}$, diode $D_{\mathrm{a}}$, output capacitor $C_{\mathrm{a}}$ and a switched capacitor cell consisting of capacitor $C_{\mathrm{a} 1}, C_{\mathrm{a} 2}$ and diode $D_{\mathrm{a} 1}, D_{\mathrm{a} 2}$. Switched capacitors can store the energy delivered from primary side of $T_{1}$ when the power switch $S_{1}$ turns on, and releases it to charge flyback output capacitor $C_{\mathrm{a}}$ through $D_{\mathrm{a}}$ when $S_{1}$ turns off. As a consequence, $T_{1}$ is able to 
transform power from primary side to secondary side during the entire switching period. $L \mathrm{kt}$, which is defined as the leakage inductor of $T_{1}$, connects the boost inductor $L_{\mathrm{ks}}$ serially, and their sum $\left(L_{\mathrm{kt}}+L_{\mathrm{ks}}\right)$ can be regarded as the equivalent leakage inductor $L \mathrm{k}$.

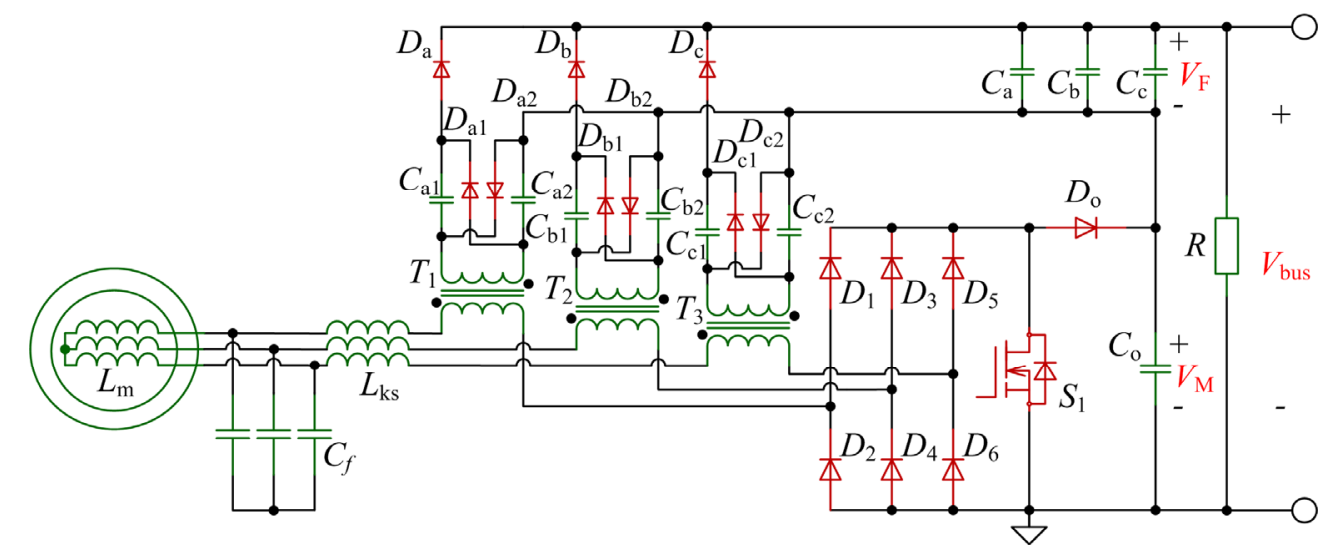

Figure 9. The circuit topology of the proposed converter.

In order to further improve the performance at low input voltage, all of the flyback output capacitors $C_{\mathrm{a}}, C_{\mathrm{b}}, C_{\mathrm{c}}$ and the boost output capacitor $C_{\mathrm{o}}$ employ film capacitors with small capacitance and small volume instead of electrolytic capacitors. On one hand, by doing so, the converter can prevent the large current leakage and large losses introduced by electrolytic capacitors, and thus can achieve weak energy collection. On the other hand, the adoption of film capacitors can also lead to larger voltage ripples, since the capacitance is small. To restrain the voltage ripples, $C_{\mathrm{a}}, C_{\mathrm{b}}, C_{\mathrm{c}}$ are designed to connect in parallel, for the reason that the ripple of each phase is identical in amplitude and $120^{\circ}$ behind sequentially in phase and will weaken each other. $C_{\mathrm{F}}$, which consists of $C_{\mathrm{a}}, C_{\mathrm{b}}, C_{\mathrm{c}}$, is defined as the equivalent flyback output capacitor and connects $C_{o}$ serially. As a result, the voltage gain is further improved, because the flyback output voltage $V_{\mathrm{F}}$ is superimposed to the boost output voltage $V_{\mathrm{M}}$.

The comparison among the proposed AC/DC converter and other three-phase AC/DC converters are made as manifested in Table 1. According to the table, although the proposed converter has the maximum quantity of power switches and diodes, the unit-price of the chosen auxiliary diodes in flyback cells is exceedingly low (ES3G, less than $\$ 0.05 /$ pieces). Moreover, some traditional converters even need low-frequency transformers to achieve high voltage gain, which will further increase the converter cost. With a relatively low cost and good performance, the proposed AC/DC converter is competitive in small-scale WGS applications.

Table 1. Cost Comparison.

\begin{tabular}{cccccc}
\hline AC/DC Converter & $\begin{array}{c}\text { High Frequency } \\
\text { Transformer/Inductor }\end{array}$ & $\begin{array}{c}\text { Power Switch } \\
\text { Quantity }\end{array}$ & $\begin{array}{c}\text { Power Diode } \\
\text { Quantity }\end{array}$ & $\begin{array}{c}\text { Auxiliary } \\
\text { Diode Quantity }\end{array}$ & Cost \\
\hline $\begin{array}{c}\text { Diode Bridge + Boost } \\
\text { Converter }\end{array}$ & 1 & 1 & 7 & 0 & Lowest \\
PWM Converter & 3 & 6 & 0 & 0 & High \\
Matrix Converter & 3 & 9 & 0 & 0 & Highest \\
Three-phase & 3 & 1 & 7 & 0 & Low \\
$\begin{array}{c}\text { Single-switched Converter } \\
\text { Proposed Converter }\end{array}$ & 3 & 1 & 7 & 9 & Low \\
\hline
\end{tabular}




\section{Operation Principles}

\subsection{Operation States}

In this section, operating modes are analyzed in detail. To simplify the circuit analysis, several assumptions are made:

(1) All three flyback cells are symmetrical, and the corresponding components in each phase are identical.

(2) Switch $S_{1}$ and all diodes are regarded as ideal components.

(3) $V_{\mathrm{F}}, V_{\mathrm{M}}$ and input voltages are constant during a whole switching period.

From Figure 10, it can be seen that the $2 \pi$ input voltage cycle can be divided into 12 symmetrical intervals.

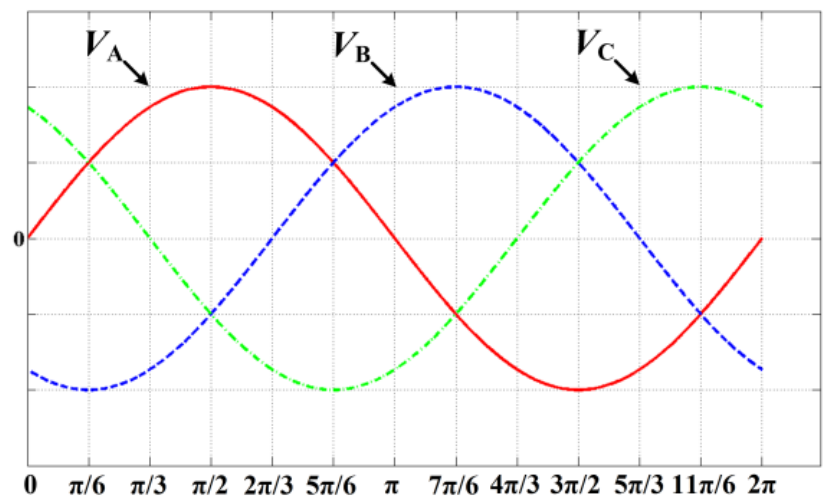

Figure 10. The waveform of the input voltage.

In each interval, the calculation methods are similar, so only take time interval within $[\pi / 2, \pi / 3]$ of phase A for instance to analyze the proposed circuit. The relationship of input voltage within this interval is:

$$
V_{\mathrm{A}}>\left|V_{\mathrm{B}}\right|>\left|V_{\mathrm{C}}\right|>0>V_{\mathrm{C}}>V_{\mathrm{B}}
$$

Since the average input voltage of $V_{\mathrm{C}}$ is very low in this interval, the impact caused by the flyback cell of phase $\mathrm{C}$ can be neglected and the circuit is assumed to be only influenced by that of phases $\mathrm{A}$ and $\mathrm{B}$. The change rates of secondary current $i_{\mathrm{PA}}$ and $i_{\mathrm{PB}}$ of transformer $T_{1}$ and $T_{2}$ can be obtained as:

$$
\frac{\mathrm{d} i_{P A}}{\mathrm{~d} t}+\frac{\mathrm{d} i_{P B}}{\mathrm{~d} t}=0
$$

In steady state, an entire switching period can be mainly divided into seven modes. Typical waves are presented in Figure 11 and equivalent circuit of each mode is shown in Figure 12. In Figure 11, $v_{\mathrm{GATE}}$ represents the control signal of switch $S_{1}, i_{\mathrm{A}}, i_{\mathrm{B}}$ and $i_{\mathrm{C}}$ represent the input current, and $u_{\mathrm{CA}}$ is the voltage across the switched capacitor $C_{\mathrm{a} 1} / C_{\mathrm{a} 2}$. 


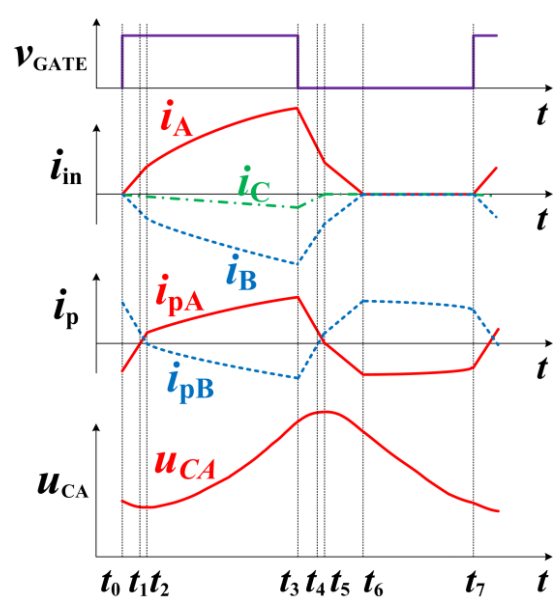

Figure 11. Key waveforms of the proposed converter.

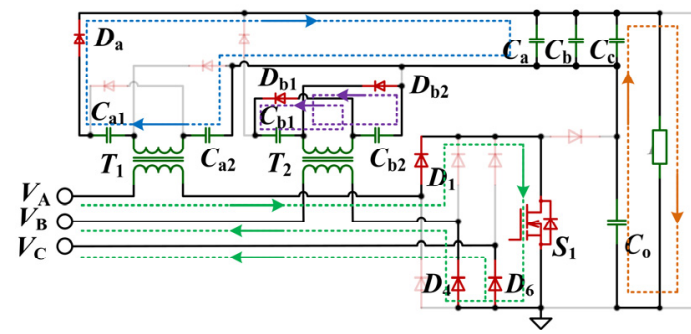

(a)

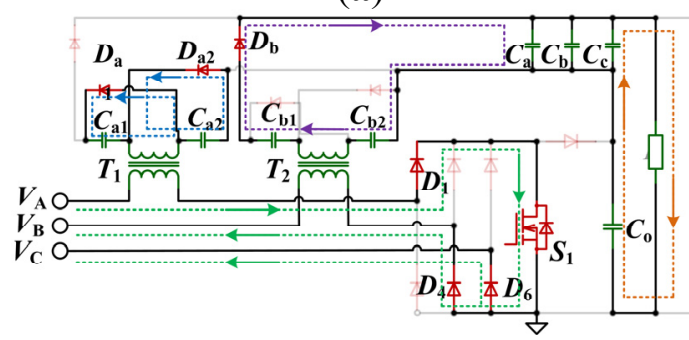

(c)

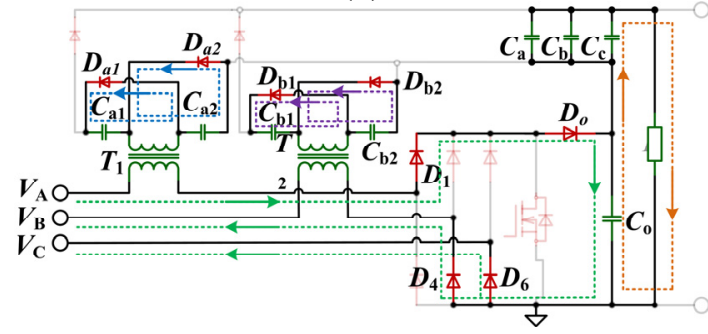

(e)

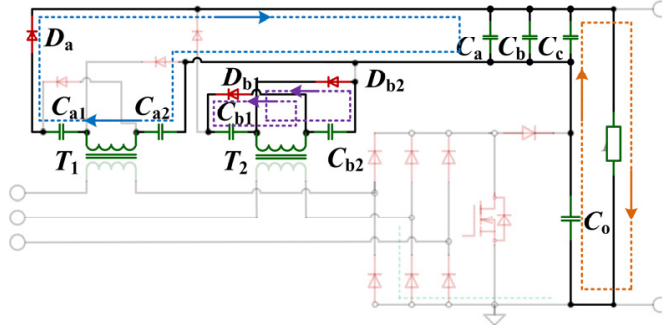

$(\mathbf{g})$

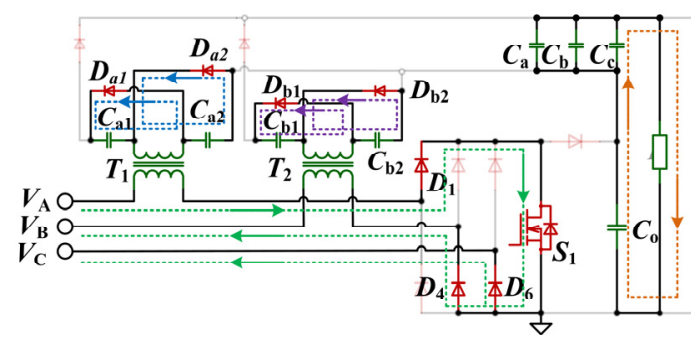

(b)

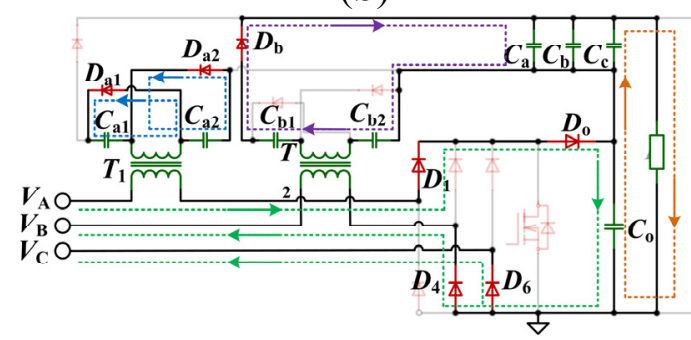

(d)

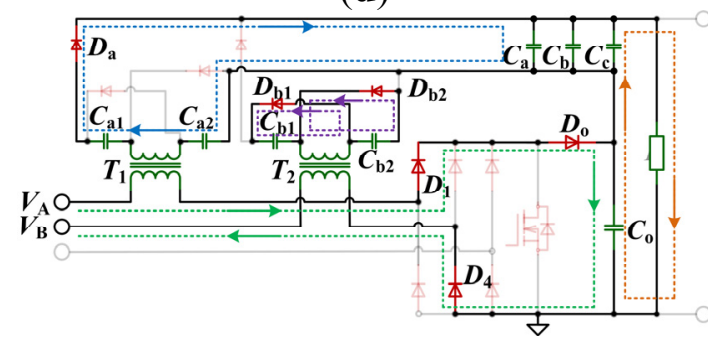

(f)

Figure 12. Equivalent circuits. (a) mode I; (b) mode II; (c) mode III; (d) mode IV; (e) mode V; (f) mode VI; (g) mode VII. 
Mode I $\left(t_{0} \sim t_{1}\right)$. According to Figure $12 \mathrm{a}$, switch $S_{1}$ turns on at the beginning of this mode, and diode $D_{1}, D_{4}, D_{6}$ are forward-biased. Flyback cells have only two working states. In phase A, diode $D_{\text {a }}$ conducts, and the switched diode $D_{\mathrm{a} 1}$ and $D_{\mathrm{a} 2}$ are reverse-biased. Switched capacitor $C_{\mathrm{a} 1}$ and $C_{\mathrm{a} 2}$ in series with the secondary inductor of transformer $T_{1}$ charges the flyback output capacitor $C_{\mathrm{F}}$ (State-OFF). In phase $\mathrm{B}$, diode $D_{\mathrm{b}}$ is reverse-biased and switched diode $D_{\mathrm{b} 1}$ and $D_{\mathrm{b} 2}$ are forward-biased. Power supplied by transformer $T_{2}$ flows through $D_{\mathrm{b} 1} / D_{\mathrm{b} 2}$ to charge switched capacitor $C_{\mathrm{b} 1} / C_{\mathrm{b} 2}$ $\left(\right.$ State-ON). As a result, $i_{\mathrm{A}}$ starts to increase from zero and $i_{\mathrm{B}}, i_{\mathrm{C}}$ also rise in the opposite direction. This mode ends when $i$ PA falls down to zero.

Mode II $\left(t_{1} \sim t_{2}\right)$. As shown in Figure $12 \mathrm{~b}$, flyback cell in phase A turns to State-ON. Current $i_{\mathrm{PA}}$ begins to increase, while $i_{\mathrm{PB}}$ is decreasing. This transition interval is finished, when $i_{\mathrm{PB}}$ reaches zero at $t_{2}$.

Mode III $\left(t_{2} \sim t_{3}\right)$. From Figure 12c, flyback cell of phase B is under State-OFF. The input source stores its energy into the equivalent leakage $L_{\mathrm{k}}$ and the magnetizing inductor $L_{\mathrm{M}}$ of $T_{1}$. Current $i_{\mathrm{A}}, i_{\mathrm{B}}$ and $i_{\mathrm{C}}$ keep increasing from their initial mode value and $i_{\mathrm{PA}}, i_{\mathrm{PB}}$ increase as well. Until the moment $t_{3}$, $S_{1}$ turns off and this mode comes to the end.

Mode IV $\left(t_{3} \sim t_{4}\right)$. From Figure $12 \mathrm{~d}$, this mode starts when $S_{1}$ turns off and diode $D_{\mathrm{o}}, D_{1}, D_{4}$, and $D_{6}$ are forward-biased. The states of flyback cells stay the same with Mode III. The input sources in series with inductors $L_{\mathrm{k}}$ and $L_{\mathrm{M}}$ charges the boost cell output capacitor $C_{\mathrm{o}}$. Since the voltage across $C_{\mathrm{o}}$ is higher than the input voltage, $i_{\mathrm{A}}, i_{\mathrm{B}}, i_{\mathrm{C}}$ and $i_{\mathrm{PA}}, i_{\mathrm{PB}}$ decrease rapidly. This mode ends when $i_{\mathrm{PB}}$ reaches zero at $t_{4}$.

Mode $\mathrm{V}\left(t_{4} \sim t_{5}\right)$. According to Figure 12e, this interval is also a transition mode. Flyback cells of phase A and B are both under State-ON. Current $i_{\mathrm{PB}}$ starts to rise, while $i_{\mathrm{PA}}$ is still abating. This mode ends when $i_{\mathrm{PA}}$ equals to zero at $t_{5}$. At this time $i_{\mathrm{C}}$ also drops down to zero.

Mode VI $\left(t_{5} \sim t_{6}\right)$. From Figure $12 \mathrm{f}, i_{\mathrm{C}}$ remains zero and diode $D_{6}$ turns off. Flyback cell of phase A is under State-OFF and that of phase B turns to State-ON. The input source of phase A and B keep charging $C_{\mathrm{o}}$ with inductors $L_{\mathrm{k}}$ and $L_{\mathrm{M}}$. Current $i_{\mathrm{A}}$ and $i_{\mathrm{B}}$ continue to drop until they reach zero at $t_{6}$ simultaneously, and at this moment Mode VI is finished.

Mode VII $\left(t_{6} \sim t_{7}\right)$. It can be seen in Figure $12 \mathrm{~g}$, diode $D_{1}, D_{4}$ and $D_{0}$ turn off and the states of flyback cells do not change. Inductor $L_{\mathrm{M}}$ of $T_{1} / T_{2}$ alone transfers power from the primary side to the secondary side. Current $i_{\mathrm{A}}, i_{\mathrm{B}}, i_{\mathrm{C}}$ maintain zero, and $i_{\mathrm{PA}}, i_{\mathrm{PB}}$ reduce slowly. This mode ends when $S_{1}$ is turned on again at the moment $t 7$, and the entire switching period is ended.

\subsection{Operation Analysis}

According to the operation states and the equivalent circuits of the proposed converter, expressions of each mode are obtained, so that parameters of the converter can be optimized. Since Mode II and Mode $\mathrm{V}$ are transition modes and have little influence on the converter, they are neglected in order to simplify the circuit analysis. Parameters are defined as follows: $i_{\text {LmA }}$ represents the magnetizing current of phase A; $I_{\mathrm{PAx}}, U_{\mathrm{CAx}}$ and $I_{\mathrm{LmAx}}(x=a, b, c, d, e)$ are defined as the initial value of corresponding mode of parameter $i_{\mathrm{PA}}, u \mathrm{CA}$ and $i_{\mathrm{LmA}} ; V_{\mathrm{LmA}}$ is the voltage across the magnetizing inductor of $T_{1} ; C$ represents the capacitance of $C_{\mathrm{a} 1} / \mathrm{C}_{\mathrm{a} 2}$.

From Figure 12a, equations of Mode I is listed as: 


$$
\left\{\begin{aligned}
V_{\mathrm{A}} & =V_{\mathrm{LmA}}+L_{\mathrm{k}} \frac{d i_{\mathrm{A}}}{d t} \\
i_{\mathrm{A}} & =i_{\mathrm{LmA}}+N \cdot i_{\mathrm{PA}} \\
i_{\mathrm{PA}} & =C \frac{d u_{\mathrm{CA}}}{d t} \\
V_{\mathrm{F}} & =2 u_{\mathrm{CA}}-N \cdot V_{\mathrm{LmA}} \\
V_{\mathrm{LmA}} & =L_{\mathrm{M}} \frac{d i_{\mathrm{LmA}}}{d t}
\end{aligned}\right.
$$

By solving Equation (3), expressions of key parameter $u \mathrm{CA}$ and $i \mathrm{PA}$ is calculated as:

$$
\left\{\begin{array}{l}
u_{\mathrm{CA}}(t)=K_{\mathrm{a} 1}+K_{\mathrm{a} 2} \beta t+\frac{V_{\mathrm{F}}}{2}+\frac{N L_{\mathrm{M}}}{2\left(L_{\mathrm{k}}+L_{\mathrm{M}}\right)} V_{\mathrm{A}} \\
i_{\mathrm{PA}}(t)=-C K_{\mathrm{a} 1} \beta^{2} t+C K_{\mathrm{a} 2} \beta
\end{array}\right.
$$

In Equation (4), $K_{\mathrm{a} 1}, K_{\mathrm{a} 2}$ represent the mode coefficients of Mode I, and $\beta$ is defined as the equivalent mode angular frequency:

$$
\begin{aligned}
& \left\{\begin{array}{l}
u_{\mathrm{CA}}(t)=K_{\mathrm{a} 1}+K_{\mathrm{a} 2} \beta t+\frac{V_{\mathrm{F}}}{2}+\frac{N L_{\mathrm{M}}}{2\left(L_{\mathrm{k}}+L_{\mathrm{M}}\right)} V_{\mathrm{A}} \\
i_{\mathrm{PA}}(t)=-C K_{\mathrm{a} 1} \beta^{2} t+C K_{\mathrm{a} 2} \beta
\end{array}\right. \\
& \beta=\sqrt{\frac{2\left(L_{k}+L_{M}\right)}{N^{2} C L_{M} L_{k}}}
\end{aligned}
$$

The mode duty cycle $d_{\mathrm{a}}$ can be achieved as Equation (7), where $T_{\mathrm{s}}$ is the switching period and $I_{\mathrm{PB} 0}$ represents the initial value of Mode I:

$$
d_{\mathrm{a}}=\frac{I_{\mathrm{PB} 0}}{T_{\mathrm{S}} C K_{\mathrm{a} 1} \beta^{2}}
$$

I $\mathrm{PB} 0$ can be approximately obtained as:

$$
I_{\mathrm{PB} 0} \approx I_{\mathrm{PA} 1}-I_{\mathrm{PA} 0}
$$

By adopting similar approach, the mode expressions and the duty cycle of each mode can be obtained as well.

In Mode III, $u$ CA and $i_{\mathrm{PA}}$ are:

$$
\left\{\begin{array}{l}
u_{\mathrm{CA}}(t)=K_{\mathrm{b} 1} \cos (\alpha t)+K_{\mathrm{b} 2} \sin (\alpha t)+\frac{N L_{\mathrm{M}}}{L_{\mathrm{k}}+L_{\mathrm{M}}} V_{\mathrm{A}} \\
i_{\mathrm{PA}}(t)=-2 C K_{\mathrm{b} 1} \alpha \sin (\alpha t)+2 C K_{\mathrm{b} 2} \alpha \cos (\alpha t)
\end{array}\right.
$$

Equivalent mode angular frequency $\alpha$ and mode coefficients $K_{\mathrm{b} 1}, K_{\mathrm{b} 2}$ are described as:

$$
\begin{aligned}
& \left\{\begin{array}{l}
K_{\mathrm{b} 1}=U_{\mathrm{CA} 1}-\frac{N L_{\mathrm{M}}}{L_{\mathrm{k}}+L_{\mathrm{M}}} V_{\mathrm{A}} \\
K_{\mathrm{b} 2}=\frac{I_{\mathrm{PA} 1}}{2 C \alpha}
\end{array}\right. \\
& \alpha=\sqrt{\frac{L_{\mathrm{k}}+L_{\mathrm{M}}}{2 N^{2} C L_{\mathrm{M}} L_{\mathrm{k}}}}
\end{aligned}
$$


The duty cycle of Mode III is:

$$
d_{\mathrm{b}}=D-d_{\mathrm{a}}=D-\frac{I_{\mathrm{PB} 0}}{T_{\mathrm{S}} C K_{\mathrm{a} 1} \beta^{2}}
$$

In Mode IV, $u$ CA and $i_{\mathrm{PA}}$ are:

$$
\left\{\begin{array}{l}
u_{\mathrm{CA}}(t)=K_{\mathrm{c} 1}+K_{\mathrm{c} 2} \alpha t+\frac{N L_{\mathrm{M}}}{L_{\mathrm{k}}+L_{\mathrm{M}}}\left(V_{\mathrm{A}}-\frac{2}{3} V_{\mathrm{M}}\right) \\
i_{\mathrm{PA}}(t)=-2 C K_{\mathrm{c} 1} \alpha^{2} t+2 C K_{\mathrm{c} 2} \alpha
\end{array}\right.
$$

Mode coefficients $K_{\mathrm{c} 1}, K_{\mathrm{c} 2}$ are described as:

$$
\left\{\begin{array}{l}
K_{\mathrm{c} 1}=U_{\mathrm{CA} 2}-\frac{N L_{\mathrm{M}}}{L_{\mathrm{k}}+L_{\mathrm{M}}}\left(V_{\mathrm{A}}-\frac{2}{3} V_{\mathrm{M}}\right) \\
K_{\mathrm{c} 2}=\frac{I_{\mathrm{PA} 2}}{2 C \alpha}
\end{array}\right.
$$

The duty cycle of Mode IV is:

$$
d_{\mathrm{c}}=\frac{K_{\mathrm{c} 2}}{T_{\mathrm{s}} K_{\mathrm{c} 1} \alpha}
$$

In Mode $\mathrm{VI}, u \mathrm{CA}$ and $i_{\mathrm{PA}}$ are:

$$
\left\{\begin{array}{l}
u_{\mathrm{CA}}(t)=K_{\mathrm{d} 1} \cos (\beta t)+\frac{V_{\mathrm{F}}}{2}+\frac{N L_{\mathrm{M}}\left(V_{\mathrm{A}}-V_{\mathrm{B}}-V_{\mathrm{M}}\right)}{4\left(L_{\mathrm{k}}+L_{\mathrm{M}}\right)} \\
i_{\mathrm{PA}}(t)=-C K_{\mathrm{d} 1} \beta \sin (\beta t)
\end{array}\right.
$$

Mode coefficient $K_{\mathrm{d} 1}$ is described as:

$$
K_{\mathrm{d} 1}=U_{\mathrm{CA} 3}-\frac{V_{\mathrm{F}}}{2}-\frac{N L_{\mathrm{M}}\left(V_{\mathrm{A}}-V_{\mathrm{B}}-V_{\mathrm{M}}\right)}{4\left(L_{\mathrm{k}}+L_{\mathrm{M}}\right)}
$$

The duty cycle of Mode VI is:

$$
d_{\mathrm{d}}=-\frac{I_{\mathrm{LmA} 3}}{\frac{2 K_{\mathrm{d} 1}}{N L_{\mathrm{M}}}+\frac{V_{\mathrm{A}}-V_{\mathrm{B}}-V_{\mathrm{M}}}{2\left(L_{\mathrm{k}}+L_{\mathrm{M}}\right)}-N C K_{\mathrm{d} 1} \beta^{2}} \cdot \frac{1}{T_{\mathrm{S}}}
$$

In Mode VII, $u$ CA and $i_{\mathrm{PA}}$ are:

$$
\left\{\begin{array}{l}
u_{\mathrm{CA}}=K_{\mathrm{e} 1} \cos (\theta t)+K_{\mathrm{e} 2} \sin (\theta t)+\frac{V_{\mathrm{F}}}{2} \\
i_{\mathrm{PA}}=-C K_{\mathrm{e} 1} \theta \sin (\theta t)+C K_{\mathrm{e} 2} \theta \cos (\theta t)
\end{array}\right.
$$

Equivalent mode angular frequency $\theta$ and mode coefficients $K_{\mathrm{e} 1}, K_{\mathrm{e} 2}$ are described as:

$$
\begin{gathered}
\left\{\begin{array}{l}
K_{\mathrm{e} 1}=U_{\mathrm{CA} 4}-\frac{V_{\mathrm{F}}}{2} \\
K_{\mathrm{e} 2}=\frac{I_{\mathrm{PA} 4}}{C \theta}
\end{array}\right. \\
\theta=\sqrt{\frac{2}{N^{2} C L_{\mathrm{M}}}}
\end{gathered}
$$


The duty cycle of Mode VII is:

$$
d_{\mathrm{e}}=1-D-d_{\mathrm{c}}-d_{\mathrm{d}}
$$

Although the mode states and expressions have already been analyzed, the numerical solution of the key parameters still cannot be achieved, as additional equations must be found. Since the output voltage of flyback cell $V_{\mathrm{F}}$ and that of boost cell $V_{\mathrm{M}}$ are regarded as constant values, the ampere-second balance principle of capacitor is adopted as:

$$
\left\{\begin{aligned}
\int_{0}^{d_{\mathrm{c}} T_{\mathrm{S}}} i_{\mathrm{A}} \mathrm{d} t & +\int_{0}^{d_{\mathrm{d}} T_{\mathrm{S}}} i_{\mathrm{A}} \mathrm{d} t=\int_{0}^{T_{\mathrm{S}}} i_{\mathrm{o}} \mathrm{d} t \\
\int_{0}^{d_{\mathrm{b}} T_{\mathrm{S}}} i_{\mathrm{PB}} \mathrm{d} t & +\int_{0}^{d_{\mathrm{d}} T_{\mathrm{S}}} i_{\mathrm{PB}} \mathrm{d} t+\int_{0}^{d_{\mathrm{d}} T_{\mathrm{S}}} i_{\mathrm{PA}} \mathrm{d} t \\
& +\int_{0}^{d_{\mathrm{e}} T_{\mathrm{S}}} i_{\mathrm{PA}} \mathrm{d} t+\int_{0}^{d_{\mathrm{a}} T_{\mathrm{S}}} i_{\mathrm{PA}} \mathrm{d} t=-\int_{0}^{T_{\mathrm{S}}} i_{\mathrm{o}} \mathrm{d} t
\end{aligned}\right.
$$

Where $i_{\mathrm{o}}$ and $i_{\mathrm{PB}}$ can be described as Equation (24) and $V_{\text {bus }}$ is the total output voltage of the circuit:

$$
\left\{\begin{array}{l}
i_{\mathrm{o}}=\frac{V_{\text {bus }}}{R}=\frac{V_{\mathrm{F}}+V_{\mathrm{M}}}{R} \\
-i_{\mathrm{PB}} \approx i_{\mathrm{PA}}-i_{\mathrm{o}}
\end{array}\right.
$$

Combining and solving these mode expressions and Equations (23) and (24), finally the numerical solution of the main parameters is obtained.

\subsection{Parameter Design}

Since the proposed converter is applied in small-scaled WGS, two requirements must be met to guarantee normal operation:

(1) When the input voltage is very low, high voltage gain is the main optimized purpose, because a relatively high output voltage is needed to act as the supply of the post-stage inverter for further grid-tie

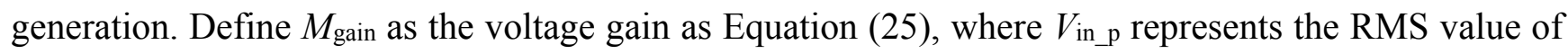
the input phase voltage:

$$
M_{\text {gain }}=\frac{V_{\text {bus }}}{V_{\text {in } \_p}}
$$

Based on the calculation results, the voltage gain $M_{\text {gain }}$ is primarily decided by parameters of transformer turns ratio $N$, equivalent leakage inductor $L_{\mathrm{k}}$ and duty cycle $D$. To further illustrate the influence on $M$ gain caused by $N, L_{\mathrm{k}}$ and $D$, Figure 13 is drawn, where Figure $13 \mathrm{a}-\mathrm{c}$ represents the relationship among $M$ gain and $L \mathrm{k}, D$, when $N$ is equal to 1,3 and 5 .

As it is shown, a larger $D$ and a smaller $L_{\mathrm{k}}$ lead to a higher $M_{\text {gain, }}$, namely when a high voltage gain is needed at low input voltage, a large duty cycle and a small equivalent leakage inductor should be chosen to satisfy the demands. Accordingly, the value range of small duty cycle or large leakage inductor should be abandoned. However, extremely high $D$ or extremely small $L_{\mathrm{k}}$ may result in low efficiency, and should be prevented also. 


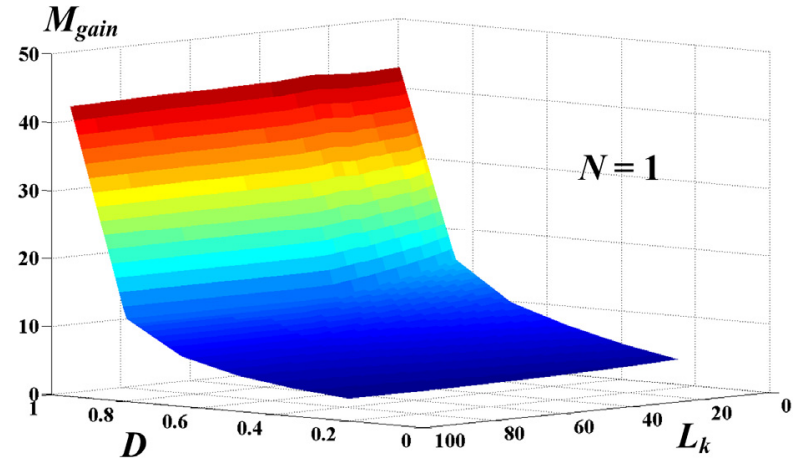

(a)

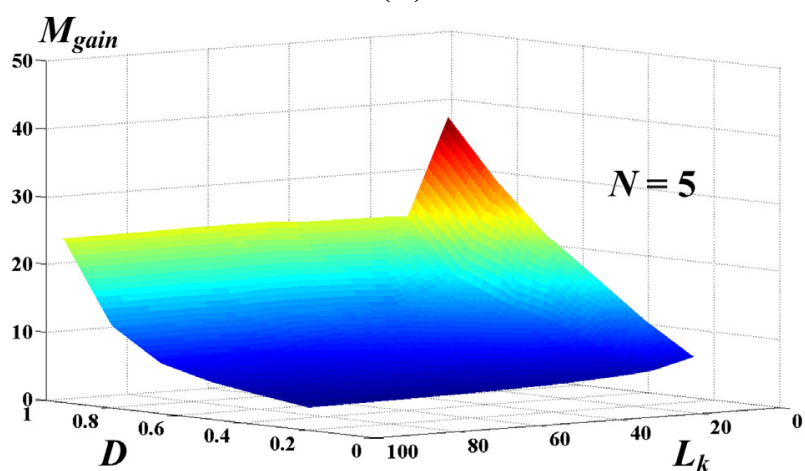

(c)

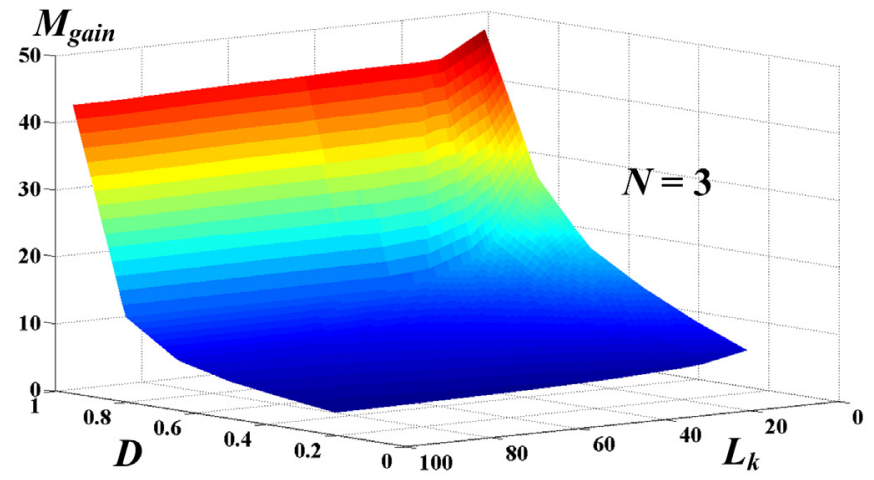

(b)

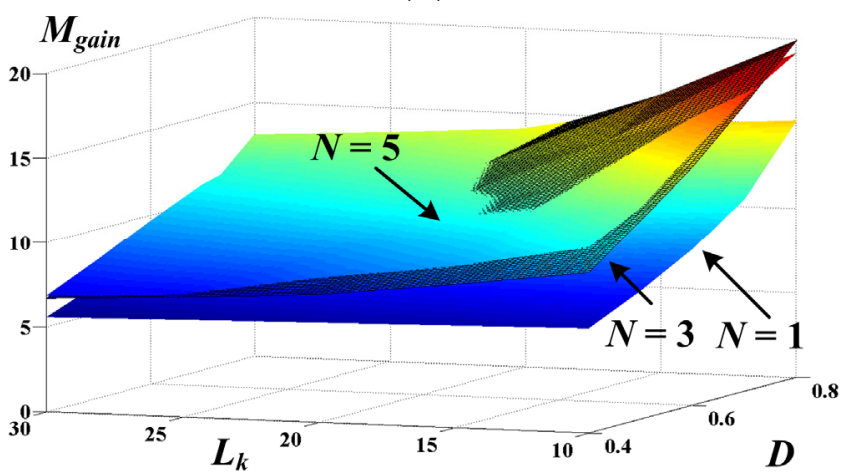

(d)

Figure 13. Relationship of $M_{\text {gain }}$ and $N, D, L_{\mathrm{k}}$. (a) case of $N=1$; (b) case of $N=3$; (c) case of $N=5$; (d) case of chosen area.

Thus, in Figure $13 \mathrm{~d}$, the relationship of $M_{\text {gain }}$ and $N, L \mathrm{k}, D$ within a reasonable limited value range, which covers a relatively high $D$ and a small $L_{\mathrm{k}}$ area, is shown. Obviously, both the voltage gain of $N=3, M_{\text {gain }}(N=3)$ and that of $N=5, M_{\text {gain }}(N=5)$ are higher than that of $N=1, M_{\text {gain }}(N=1)$. When $D$ is relatively high and $L_{\mathrm{k}}$ is small, $M_{\text {gain }}(N=3)$ is slightly larger than $M_{\text {gain }}(N=5)$, and when $D$ is reduced, $M$ gain $(N=3)$ is lower than $M_{\text {gain }}(N=5)$. Therefore, $M_{\text {gain }}(N=3)$ is more suitable for the proposed converter, since a larger $M_{\text {gain }}$ at high $D$ is needed at low input voltage, and a limited $M_{\text {gain }}$ at relatively low $D$ to ensure normal operation.

(2) When the input voltage is in the rated situation, instead of pursuing high voltage gain, high conversion efficiency is of the greatest importance in the proposed converter. Moreover, sinusoidal input current waves in phase with the input phase voltages are also needed to ensure a high power factor. At this time, the input voltage has increased to a high level, and a medium voltage gain is enough for the requirement of DC-link. Thus, a very large $M_{\text {gain }}$ is unnecessary. Although flyback cells contribute to high voltage gain at low input voltage, they would also introduce distortions into the input current, and consequently reduce the conversion efficiency. It is for the reason that along with the increase of the flyback output voltage $V_{\mathrm{F}}$, the secondary current of the transformers $i_{\mathrm{pA}}, i_{\mathrm{pB}}$ and $i_{\mathrm{pC}}$ will also get larger and larger as the result. The secondary currents will lead to a growing influence on the primary side input current $i_{\mathrm{A}}, i_{\mathrm{B}}$ and $i_{\mathrm{C}}$ respectively and cause distortions. Define $M_{\mathrm{FM}}$ as the distortion factor as Equation (26), where $V_{\mathrm{F}}$ is the output voltage of flyback cells and $V_{\mathrm{M}}$ is that of the boost cell: 


$$
M_{F M}=\frac{V_{F}}{V_{M}}
$$

From Equation (26), it can be seen that the larger the $M_{\mathrm{FM}}$ is, the greater proportion $V_{\mathrm{F}}$ possesses in the total output voltage of the converter $V_{\text {bus }}\left(V_{\text {bus }}=V_{\mathrm{F}}+V_{\mathrm{M}}\right)$, and thus the greater the distortions of input currents are. The influence on the input current caused by $M_{\mathrm{FM}}$ is presented in Figure 14.

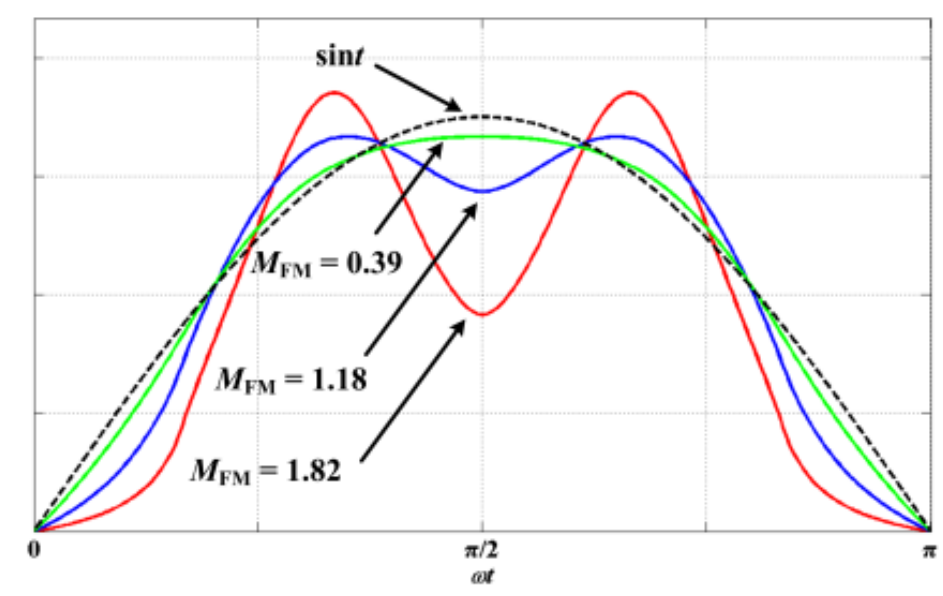

Figure 14. Influence on the input current by $M_{\mathrm{FM}}$.

The distortion factor $M_{\mathrm{FM}}$ is also decided by parameter $N, D$ and $L_{\mathrm{k}}$. Their relationships are presented in Figure 15, where Figure 15a-c illustrates the varying trends of different turns ratios $(N=1,3$ and 5$)$.

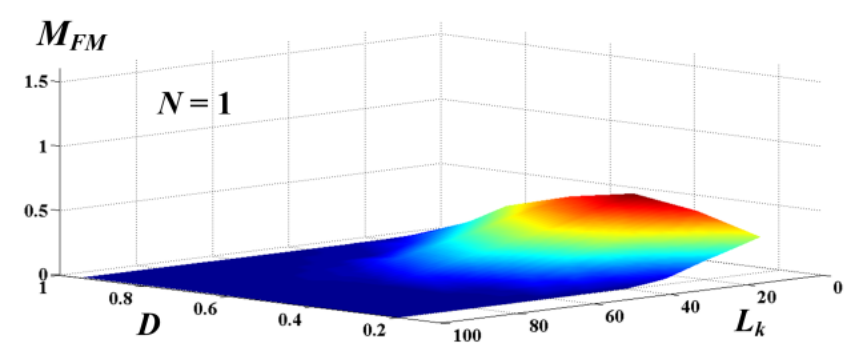

(a)

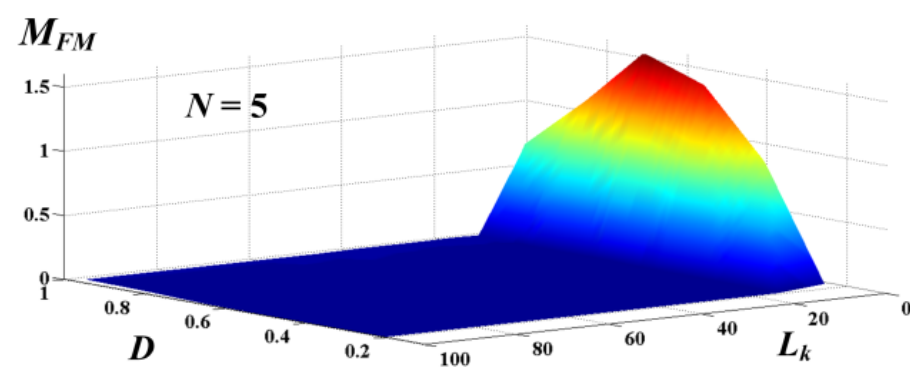

(c)

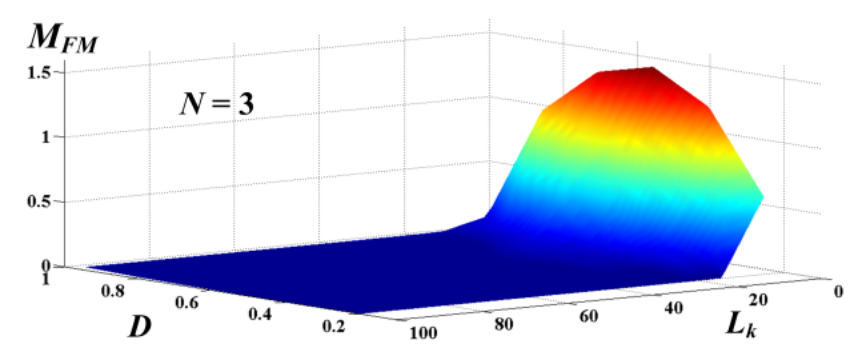

(b)

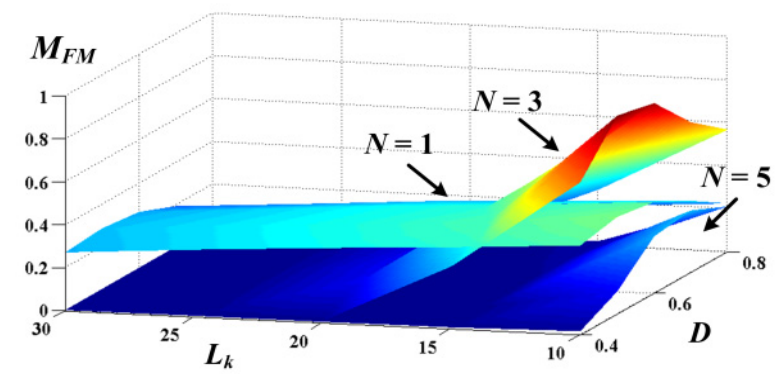

(d)

Figure 15. Relationship of $M_{\mathrm{FM}}$ and $N, D, L_{\mathrm{k}}$. (a) case of $N=1$; (b) case of $N=3$; (c) case of $N=5 ;(\mathbf{d})$ case of chosen area. 
As shown, when $L_{\mathrm{k}}$ is constant and along with the increase of $D, M_{\mathrm{FM}}$ will rise up at the beginning until reaching its peak at around $D=0.6$ and then fall down. At the same time, when $D$ is constant, $M \mathrm{FM}$ will present a growing trend if $L_{\mathrm{k}}$ keeps decreasing. According to the previous analysis, low $M_{\mathrm{FM}}$ is demanded, and by choosing a large $L_{\mathrm{k}}$, the converter can obtain high efficiency at rated input voltage as shown in Figure $15 \mathrm{a}-\mathrm{c}$, but a large $L_{\mathrm{k}}$ will contradict the requirement of high $M_{\text {gain. }}$. Consequently, a suitable $M_{\mathrm{FM}}$ range should be found instead of adopting the $M_{\mathrm{FM}}$ as large as possible. Figure $15 \mathrm{~d}$ shows the comparison of different turn ratios $(N=1,3,5)$ in the same area as chosen by Figure $13 \mathrm{~d}$. It is shown that $M_{\mathrm{FM}}$ of $N=1, M_{\mathrm{FM}}(N=1)$, varies slightly and keeps its value around 0.4 , which is larger than that of $N=3, M_{\mathrm{FM}}(N=3)$, and $N=5, M_{\mathrm{FM}}(N=5)$ when $L_{\mathrm{k}}$ varies from 15 to $30 \mu \mathrm{H}$. Moreover, $M_{\text {gain }}(N=1)$ is also small and can't provide a high enough voltage gain, thus $M_{\mathrm{FM}}(N=1)$ should not be accepted. $M_{\mathrm{FM}}(N=5)$ remains smaller than $M_{\mathrm{FM}}(N=3)$ in the chosen area and seems to have a better performance when the input voltage is at rated. However, under the condition of $M_{\mathrm{FM}}(N \geq 5)$, $V_{\mathrm{F}}$ is much smaller than $V_{\mathrm{M}}$ and the function of flyback cells can be neglected. Characters of the proposed topology are almost the same with that of the three-phase single-switch boost converter. This is because the secondary transformer currents $i_{\mathrm{pA}}, i_{\mathrm{pB}}$ and $i_{\mathrm{pC}}$ are $N$ times smaller than that of primary sides, which are limited by the input currents $i_{\mathrm{A}}, i_{\mathrm{B}}$ and $i_{\mathrm{C}}$ as:

$$
N \cdot i_{\mathrm{Px}}=i_{\mathrm{x}}-i_{\mathrm{Lmx}}<i_{\mathrm{x}} \quad(\mathrm{x}=\mathrm{A}, \mathrm{B}, \mathrm{C})
$$

If $N$ is larger, the $i_{\mathrm{Px}}$ is tends to be very small, and thus the flyback cells seems not to function at all and can be neglected. Moreover, if a certain $L_{\mathrm{k}}$ value is given, the input current peak of $M_{\mathrm{FM}}(N=5)$ is always higher than that of $M_{\mathrm{FM}}(N=3)$ under the case of identical input voltage, voltage gain $M_{\text {gain }}$ and thus identical output power, which is shown in Figure 16. Higher current peak often means higher current stress, higher power loss and lower efficiency, which is against to the optimization objective, so $M_{\mathrm{FM}}(N=3)$ is selected instead of $M_{\mathrm{FM}}(N \geq 5)$. What's more, the traditional three-phase single-switch Boost converter can also obtain high voltage gain through adopting very small boost inductors, but its input current peak is much higher than the proposed converter as well.

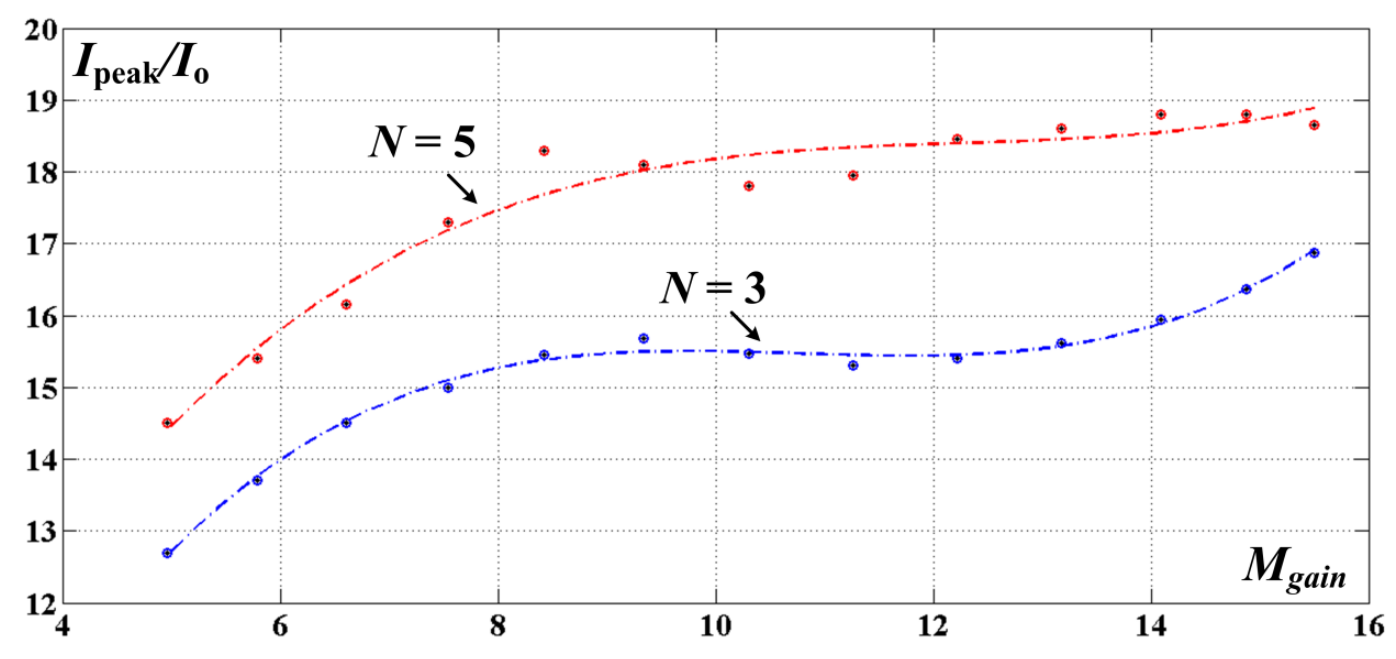

Figure 16. Comparison of input current peaks.

As a result, the main optimization purpose can be described as follows: when low input voltage is supplied, in order to provide an adequate DC-link voltage level, obtaining high voltage gain is the 
primary design goal; when input voltage is at rated levels, the primary objective is to guarantee high efficiency and sine-shaped input current waveforms, because at this moment no extremely high voltage gain is needed and the DC-link voltage should be maintained within a normal operation range. Since the variation trend of $M_{\text {gain }}$ and $M_{\mathrm{FM}}$ are not same, a trade-off optimized parameters should be given to meet both of the demands for efficiency and voltage gain: a voltage gain larger than 12 is required when the input voltage is low, and $M_{\mathrm{FM}}$ is designed to be lower than 0.4. According to Figures $13 \mathrm{~d}$ and $15 \mathrm{~d}, L_{\mathrm{k}}$ should be designed within $15 \sim 20 \mu \mathrm{H}$ to achieve high voltage gain of $8 \sim 18$, and low distortion factor of $0.1 \sim 0.4$. The appropriate parameters are selected and presented as shown in Table 2 .

Table 2. Main parameters of the proposed converter.

\begin{tabular}{cc}
\hline Parameters & Value \\
\hline Filter Capacitors $C_{\mathrm{f}}$ & $0.32 \mu \mathrm{F}$ \\
Switched Capacitors $C_{\mathrm{a} 1} / C_{\mathrm{a} 2}$ & $2 \mu \mathrm{F}$ \\
Flyback Output Capacitors $C_{\mathrm{a}}$ & $40 \mu \mathrm{F}$ \\
Boost Output Capacitors $C_{\mathrm{o}}$ & $40 \mu \mathrm{F}$ \\
Equivalent Leakage Inductor $L_{\mathrm{k}}$ & $18 \mu \mathrm{H}$ \\
Turn Ratio $N$ & 3 \\
Load Resistance $R$ & $440 \mathrm{Ohm}$ \\
Switching Frequency $f_{\mathrm{S}}$ & $100 \mathrm{kHz}$ \\
\hline
\end{tabular}

For further analysis, the relationship of $M_{\mathrm{FM}}, M_{\mathrm{gain}}, M_{\mathrm{F}}$ and $M_{\mathrm{M}}$ against $D$ for $L_{\mathrm{k}}=18 \mu \mathrm{H}$ is given in Figure 17, where $M_{\text {gain, }} M_{\mathrm{F}}$ and $M_{\mathrm{M}}$ are the voltage gain of $V_{\mathrm{F}}, V_{\mathrm{M}}$ and $V_{\text {bus. }} M_{\mathrm{FM}}$ reaches its peak value 0.35 at $D=0.6$. Voltage gain $M_{\text {gain }}$ is larger than 12 when $D$ is higher than 0.6 , which is well suitable for the optimization design.

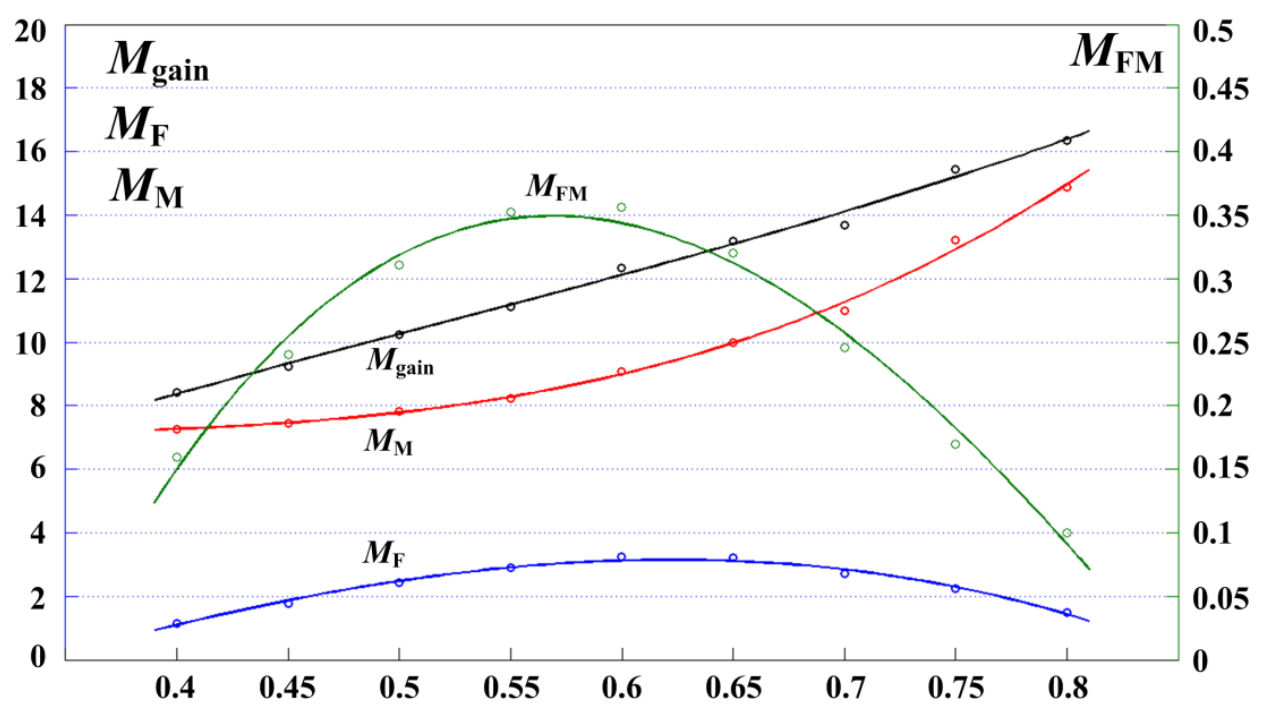

Figure 17. Relationship of $M_{\mathrm{FM}}$ and voltage gain of $V_{\mathrm{F}}, V_{\mathrm{M}}$ and $V_{\text {bus }}$ against $D$ at $L_{\mathrm{k}}=18 \mu \mathrm{H}$. 


\subsection{Power Devices Selection}

\subsubsection{Power Switch and Diode Selection}

The power devices are selected according to the rated power $(400 \mathrm{~W})$. Based on the calculation result from mode expressions and Equations (23) and (24), the maximum current and voltage of the power devices at rated are obtained and presented in Table 3. For safety consideration, 1.5 times current/voltage margins are also provided. The types of the devices are also given in Table 3.

Table 3. Power devices selection.

\begin{tabular}{cccc}
\hline Components & $\begin{array}{c}\text { Calculated Max } \\
\text { Instantaneous Current }\end{array}$ & $\begin{array}{c}\text { Calculated Max } \\
\text { Instantaneous Voltage }\end{array}$ & Selected Devices \\
\hline Power Switch & $16 \mathrm{~A}$ & $350 \mathrm{~V}$ & FCH47N60N \\
Power Diode & $16 \mathrm{~A}$ & $350 \mathrm{~V}$ & BYC30-600P \\
Auxiliary Diode & $1.7 \mathrm{~A}$ & $12 \mathrm{~V}$ & ES3G \\
\hline
\end{tabular}

\subsubsection{Transformer Design}

According to the analysis in Section 3.2, the transformer turns ratio $N=3$ is chosen. The turns of the primary side of the transforms $n_{1}$ can be calculated as:

$$
n_{1}=\frac{j A_{\mathrm{w}} k_{\mathrm{w}}}{I_{\text {in_max }}}
$$

Parameter $j=3.5 \mathrm{~A} / \mathrm{mm}^{2}$ represents the maximum current density, $A_{\mathrm{w}}$ is the winding area of the core, $k_{\mathrm{w}}=0.3$ is the winding factor and $I_{\text {in } \_ \text {max }}=6.75$ A represents the maximum input current at rated power. The transformer cores are designed as PC-40 PQ26/25, and from the datasheet, the $A_{\mathrm{w}}=84.5 \mathrm{~mm}^{2}$ is obtained. As a result, $n_{1}=13.1$ is calculated and chosen as 14 turns. The secondary side turns $n_{2}=42$ turns is also calculated.

\subsection{Power Losses Estimation}

Power losses should be estimated so that the conversion efficiency can be seen. The power losses include power switch $S_{1}$ loss, uncontrolled diode bridge rectifier $D_{1} \sim D_{6}$ losses, diode $D_{\mathrm{o}}$ loss, transformer losses and power losses of the flyback cells.

\subsubsection{Uncontrolled Diode Bridge Rectifier $\mathrm{D}_{1} \sim \mathrm{D}_{6}$}

In order to estimate the power loss of the diode bridge rectifies, the average current through each diode should be found as Equation (29), where $I_{\mathrm{DTs}}, i_{\text {peak_A }}, I_{\mathrm{D} 1}$ and $P_{\mathrm{D} 1}$ represent the average current of $D_{1}$ in one switching period, peak value of $i_{\mathrm{A}}$ in one switching period, average current of $D_{1}$ and power loss of $D_{1}$ respectively:

$$
I_{\mathrm{DTs}}=\frac{1}{T_{\mathrm{S}}} \int_{0}^{\left(1-d_{\mathrm{e}}\right) T_{\mathrm{S}}} i_{\mathrm{D} 1} d t=\frac{1}{T_{\mathrm{S}}} \int_{0}^{\left(1-d_{\mathrm{e}}\right) T_{\mathrm{S}}} i_{\mathrm{A}} d t
$$

Equation (29) can be approximated as: 


$$
\begin{aligned}
I_{\mathrm{DTs}} & \approx \frac{1}{T_{\mathrm{S}}} \frac{i_{\text {peak_A }}}{2}\left(1-d_{\mathrm{e}}\right) T_{\mathrm{S}} \\
& =\frac{\left(1-d_{\mathrm{e}}\right)}{2} i_{\text {peak_A }}
\end{aligned}
$$

Where $i_{\text {peak_A }}$ can be further approximated as:

$$
i_{\text {peak } \_\mathrm{A}} \approx \frac{V_{\mathrm{A}} \cdot \sin \omega T}{L_{\mathrm{k}}} \cdot D T_{\mathrm{S}}
$$

Therefore, $I_{\mathrm{D} 1}$ is estimated as:

$$
\begin{aligned}
I_{\mathrm{D} 1} & =\frac{1}{2 \pi} \int_{0}^{\pi} \frac{V_{\mathrm{A}} \cdot \sin \omega T}{L_{\mathrm{k}}} \cdot D T_{\mathrm{S}} \cdot \frac{\left(1-d_{\mathrm{e}}\right)}{2} \cdot d \omega T \\
& =\frac{V_{\mathrm{A}} T_{\mathrm{S}}}{2 \pi L_{\mathrm{k}}} D \cdot\left(1-d_{\mathrm{e}}\right)
\end{aligned}
$$

The power loss of $D_{1}$ can be expressed as Equation (33), where $V_{\text {forward }}$ is the forward voltage of the chosen diode BYC30-600P:

$$
P_{\mathrm{D} 1}=I_{\mathrm{D} 1} \cdot V_{\text {forward }}
$$

Thus, the power loss of the diode bridge rectifier is achieved as:

$$
P_{\text {DioBri }}=n \cdot P_{\mathrm{D} 1}=9.67 \text { Watt }
$$

\subsubsection{Diode $\mathrm{D}_{\mathrm{o}}$}

Similarly, the average current of $D_{\mathrm{o}}$ is estimated as:

$$
\begin{aligned}
I_{\mathrm{Do}} & =6 \times \frac{1}{2 \pi} \int_{\frac{\pi}{3}}^{\frac{2 \pi}{3}} \frac{V_{\mathrm{A}} \cdot \sin \omega T}{L_{\mathrm{k}}} \cdot D T_{\mathrm{S}} \cdot \frac{\left(d_{\mathrm{c}}+d_{d}\right)}{2} \cdot d \omega T \\
& =\frac{3 V_{\mathrm{A}} T_{\mathrm{S}}}{2 \pi L_{\mathrm{k}}} D \cdot\left(d_{\mathrm{c}}+d_{d}\right)
\end{aligned}
$$

The power loss of diode $D_{\mathrm{o}}$ is expressed as:

$$
P_{\mathrm{Do}}=I_{\mathrm{Do}} \cdot V_{\text {forward }}=1.21 \mathrm{Watt}
$$

\subsubsection{Power Switch $\mathrm{S}_{1}$}

The average current of $S_{1}$ is estimated as:

$$
\begin{aligned}
I_{\mathrm{S} 1} & =6 \times \frac{1}{2 \pi} \int_{\frac{\pi}{3}}^{\frac{2 \pi}{3}} \frac{V_{\mathrm{A}} \cdot \sin \omega T}{L_{\mathrm{k}}} \cdot D T_{\mathrm{S}} \cdot \frac{D}{2} \cdot d \omega T \\
& =\frac{3 V_{\mathrm{A}} T_{\mathrm{S}}}{2 \pi L_{\mathrm{k}}} D^{2}
\end{aligned}
$$

In the proposed converter, the type of $S_{1}$ is $\mathrm{FCH} 47 \mathrm{~N} 60 \mathrm{~N}$, and its forward voltage is $V_{\text {sforward. }}$ The power loss of $S_{1}$ is:

$$
P_{\mathrm{S} 1}=I_{\mathrm{S} 1} \cdot V_{\text {Sforward }}=3.25 \mathrm{Watt}
$$




\subsubsection{Flyback Cells}

The flyback cell losses are made up of switched capacitors losses and diode $D_{\mathrm{a}}\left(D_{\mathrm{b}}, D_{\mathrm{c}}\right)$ loss, where all the diodes are ES3G.

The average current of switched capacitor $D_{\mathrm{a} 1}$ is estimated as:

$$
I_{\text {Da1 }}=\frac{1}{\pi} \int_{0}^{\pi} \frac{i_{\mathrm{PA} \text { peak }}}{2} \cdot\left(D+d_{\mathrm{c}}\right) d \omega T
$$

The power loss of $D_{\mathrm{a} 1}$ is:

$$
P_{\mathrm{Da} 1}=I_{\mathrm{Da} 1} \cdot V_{\mathrm{FBforward}}=0.3 \mathrm{Watt}
$$

The average current of $D_{\mathrm{a}}$ is:

$$
I_{\mathrm{Da}}=\frac{1}{\pi} \int_{0}^{\pi} i_{\mathrm{PA} \_ \text {peak }} \cdot\left(d_{d}+d_{\mathrm{e}}\right) d \omega T
$$

The power loss of $D_{\mathrm{a}}$ is:

$$
P_{\mathrm{Da}}=I_{\mathrm{Da}} \cdot V_{\mathrm{FBforward}}=0.32 \mathrm{Watt}
$$

Consequently, the total losses of the flyback cells can be expressed as:

$$
P_{\text {FlyBack }}=3 \times\left(P_{\text {Da }}+2 P_{\text {Da1 }}\right)=2.76 \text { Watt }
$$

\subsubsection{Transformers}

Besides power dissipated from winding resistance, the power losses of transformers also include core losses. The transformer cores are designed as PC-40 PQ26/25, where $V_{\mathrm{e}}=6,530 \mathrm{~mm}^{3}$. According to the datasheet, the core loss per volume, $P_{\mathrm{cv}}=0.0004 \mathrm{~W} / \mathrm{mm}^{3}$ at $60^{\circ} \mathrm{C}$. As a result, the core loss is:

$$
P_{\text {core }}=V_{\mathrm{e}} \cdot P_{\mathrm{cv}}=2.61 \mathrm{Watt}
$$

The average current of $i_{\mathrm{A}}$ during one switching period can be expressed as:

$$
I_{\mathrm{A}}=\frac{V_{\mathrm{A}} T_{\mathrm{S}}}{\pi L_{\mathrm{k}}} D \cdot\left(1-d_{e}\right)
$$

The RMS value of $i_{\mathrm{A}}$ is:

$$
I_{\mathrm{A} \_ \text {RMS }}=\frac{I_{\mathrm{A}}}{0.45}
$$

The copper loss is:

$$
P_{\text {copper }}=I_{\mathrm{A} \_ \text {RMS }} \cdot R_{\text {Trans }}=9.12 \text { Watt }
$$

$R$ Trans $(=0.4 \Omega)$ represents the equivalent winding resistance of the transformer. The total power losses of the transformers can be calculated as Equation (48):

$$
P_{\text {Trans }}=3 \times\left(P_{\text {core }}+P_{\text {copper }}\right)=35.19 \mathrm{Watt}
$$

Finally, the conversion efficiency at rated condition (400 W) can be achieved as Equation (49): 


$$
\begin{aligned}
\eta_{\%} & =\frac{P_{\text {rated }}}{P_{\text {rated }}+P_{\text {DioBri }}+P_{\text {Do }}+P_{\mathrm{S} 1}+P_{\text {FlyBack }}+P_{\text {Trans }}} \times 100 \% \\
& =87.97 \%
\end{aligned}
$$

Power losses of each part are summarized in Table 4.

Table 4. Power losses summary.

\begin{tabular}{cc}
\hline Components & Power Losses (Watt) \\
\hline Rectifier Bridge $D_{1} \sim D_{6}$ & 9.67 \\
Diode $D_{\mathrm{o}}$ & 1.21 \\
Power Switch $S_{1}$ & 3.25 \\
Flyback Cells & 2.76 \\
Transformers & 35.19 \\
\hline
\end{tabular}

From the table, it is seen that the most influential factor reducing the conversion efficiency is the copper losses of the transformers, because a large equivalent winding resistance $R$ Trans is introduced into the converter. For the purpose of improving the efficiency, modified transformers with small winding resistance should be employed in the next step.

\section{Experimental Results}

In order to verify the feasibility of the proposed converter, a $400 \mathrm{~W}$ prototype was made and shown in Figure 18. A front-stage PMSM is employed as the power supply. The PMSM can output a rated phase voltage of $48 \mathrm{~V} \mathrm{AC}$ at its rated wind speed of $12 \mathrm{~m} / \mathrm{s}$. To match up with the voltage level of the PMSM, the proposed converter is designed to operate with rated input phase voltage of $48 \mathrm{~V}$ AC. Besides, the DC-link voltage is required to be maintained at around $410 \sim 430 \mathrm{~V} \mathrm{DC}$, so that the post-stage inverter is able to fulfill grid-tie generation. Consequently, a voltage gain of 9 is demanded under rated condition and the correspondent duty cycle $D$ is set as 0.45 according to Figure 17 .

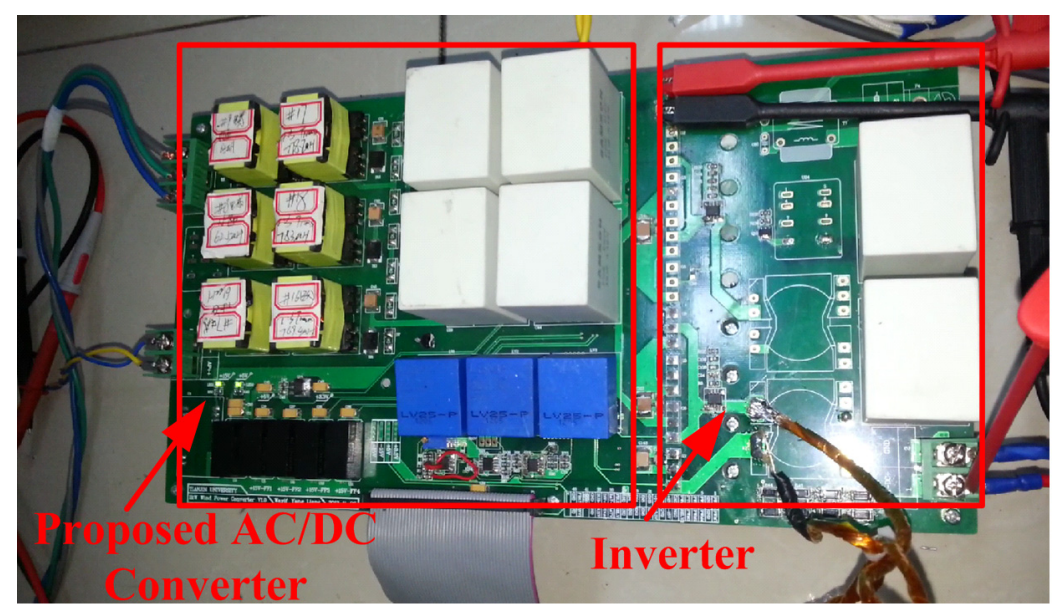

Figure 18. The proposed converter prototype.

The experimental results under the rated conditions are shown in Figure 19. In Figure 19a, line

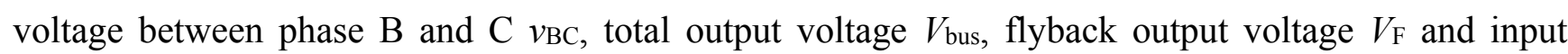
current $i_{\mathrm{A}}$ are presented, where $V_{\text {bus }}$ is $420 \mathrm{~V}, V_{\mathrm{F}}$ is $80.7 \mathrm{~V}$, and the input phase voltage $V_{\text {in-p }}$ is $45 \mathrm{~V}$ 
AC. The voltage gain $M_{\text {gain }}$ is calculated as 9.32, which matches well with the aforementioned demand. Moreover, the distortion $M_{\mathrm{FM}}$ is limited to 0.24 , so the envelope waveform of $i_{\mathrm{A}}$ exhibits a sine-shaped waveform. Figure 19b shows the PMSM output currents $i_{\mathrm{a}}, i_{\mathrm{b}}$ and $i \mathrm{c}$, where only small distortions exist in the waveforms and the THD is $7.4 \%$. Figure $19 \mathrm{c}$ shows the control signal $v_{\text {gate }}$ and the input currents $i_{\mathrm{A}}, i_{\mathrm{B}}$ and $i_{\mathrm{C}}$ in several switching cycles. At this time, since $M_{\mathrm{FM}}$ is limited and the distortion introduced by flyback cells is restrained, waveforms of current $i_{\mathrm{A}}, i_{\mathrm{B}}$ and $i_{\mathrm{C}}$ are regarded to vary linearly. After rising from zero and reaching their peaks simultaneously, $i_{\mathrm{C}}$ drops to zero at first and then $i_{\mathrm{A}}, i_{\mathrm{B}}$ also fall to zero. Figure $19 \mathrm{~d}$ illustrates the secondary current of flyback cells $i_{\mathrm{PA}}, i_{\mathrm{PB}}, i_{\mathrm{PC}}$ and voltage across the switched capacitor $C_{\mathrm{a} 1} / C_{\mathrm{a} 2} u$ cA. Furthermore, waveforms in Figure $19 \mathrm{c}, \mathrm{d}$ match well with the theoretical waveforms presented in Figure 11. The main experimental results of the converter are measured as follows: $D=0.45, V_{\text {in-P }}=45 \mathrm{~V} \mathrm{AC}, V_{\mathrm{F}}=80.7 \mathrm{~V}, V_{\text {bus }}=420 \mathrm{~V}, M_{\text {gain }}=9.32, M_{\mathrm{FM}}=0.24$, $\mathrm{THD}=7.4 \%$, PF (power factor) $=0.99$, Efficiency $\eta=87.6 \%$.

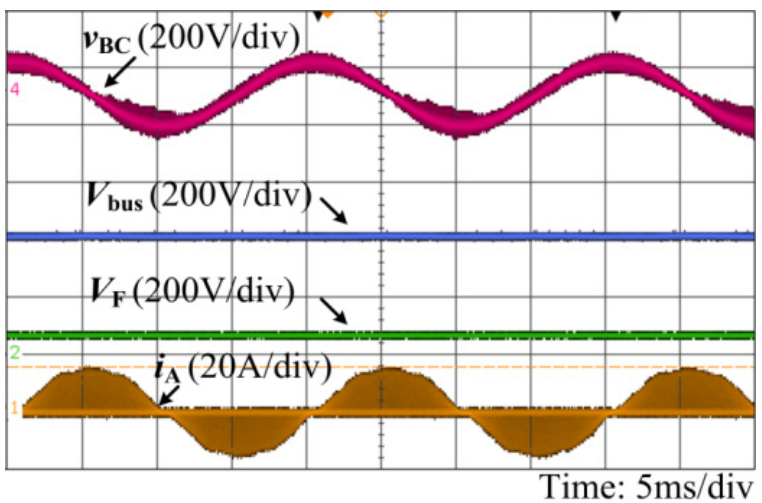

(a)

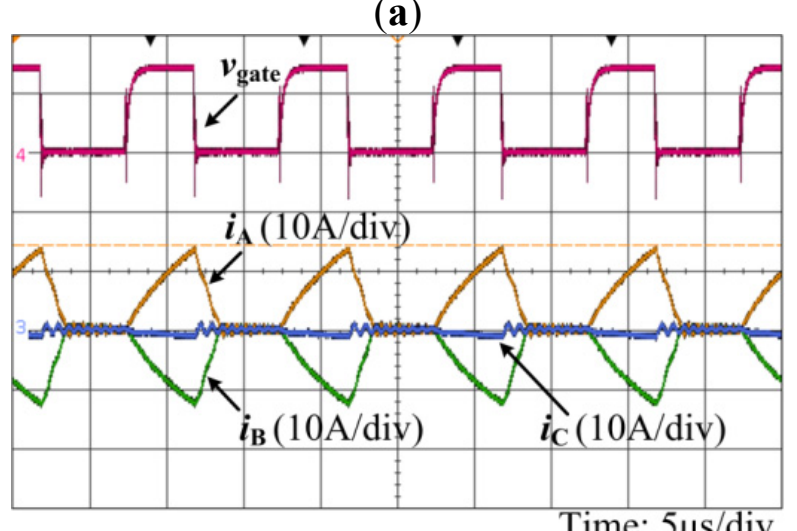

(c)

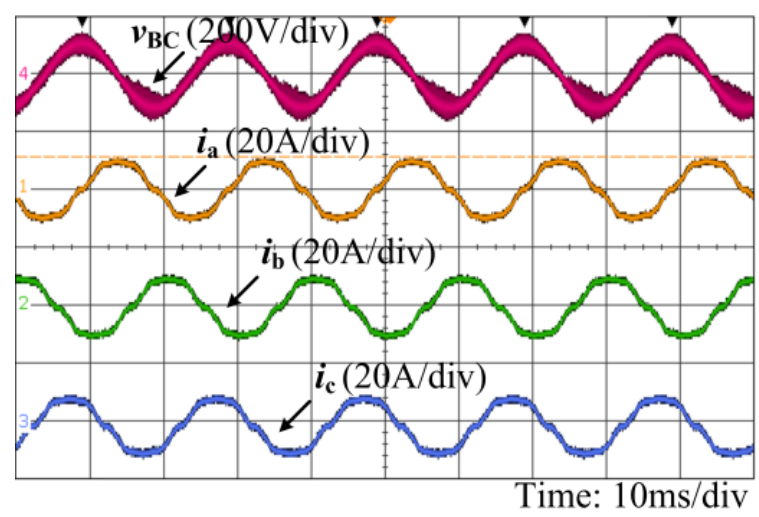

(b)

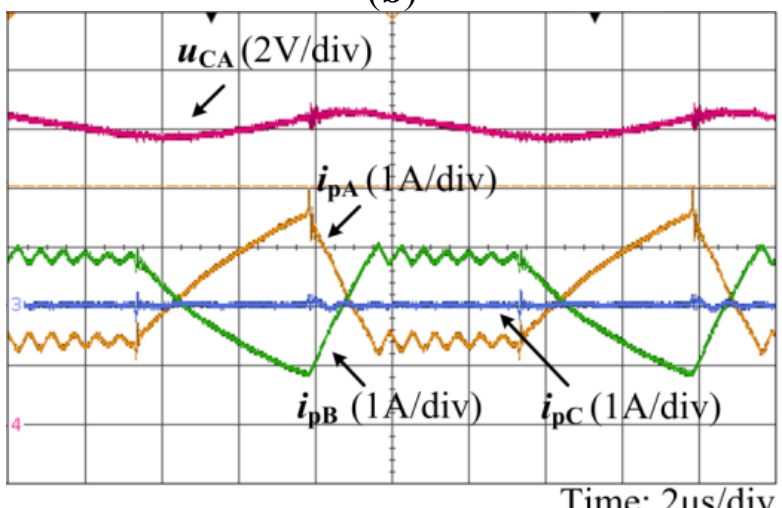

(d)

Figure 19. Experimental results under the rated conditions. (a) input line voltage, output voltage and input current; (b) input line voltage and PMSM output currents; (c) gate signal and three phase input current in detail; (d) $u$ CA and secondary currents of flyback cells.

The performance at low input voltage is also tested as shown in Figure 20, where each of the waveform represents the same voltage/current signal as that in Figure 19. By introducing the flyback cells and adopting high duty cycle $D=0.7$, the proposed converter can achieve high voltage gain at low input voltage. At this time, $V_{\text {bus }}$ is $163 \mathrm{~V}, V_{\mathrm{F}}$ is $34.6 \mathrm{~V}$ and $V_{\text {in-p }}$ is $11.6 \mathrm{~V}$ AC. The voltage gain $M$ gain reaches a relatively high level of 14 . Besides, waveforms in Figure 20c,d also match with the theoretical 
analysis. The main parameters of the converter are measured as follows: $D=0.7, V_{\text {in-P }}=11.6 \mathrm{~V} \mathrm{AC}$, $V_{\mathrm{F}}=34.6 \mathrm{~V}, V_{\text {bus }}=163 \mathrm{~V}, M_{\text {gain }}=14, M_{\mathrm{FM}}=0.27, \mathrm{THD}=8.2 \%$, PF (power factor) $=0.99$, Efficiency $\eta=81.1 \%$.

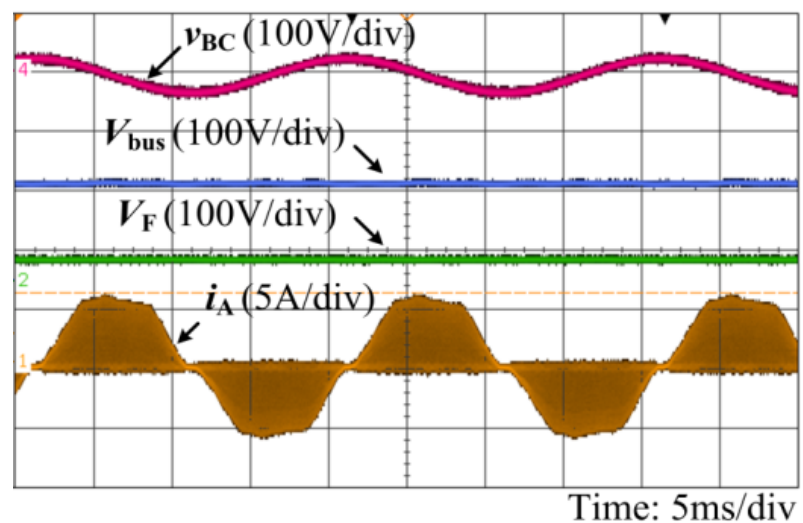

(a)

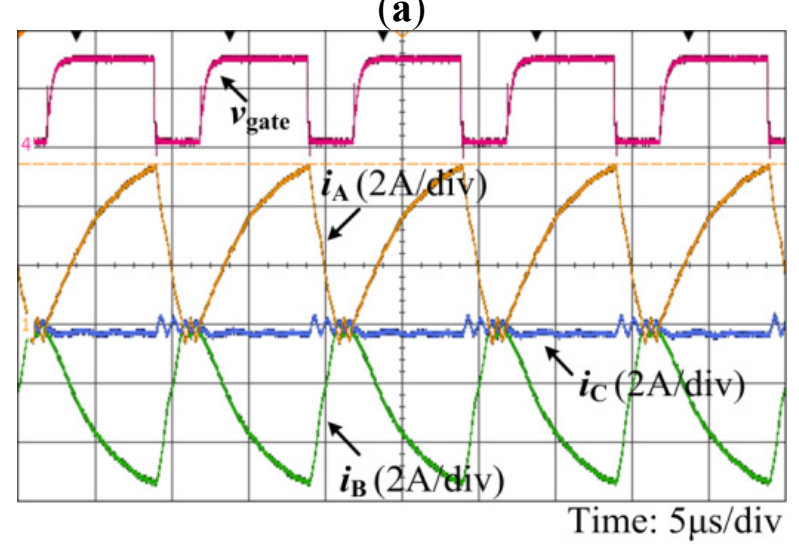

(c)

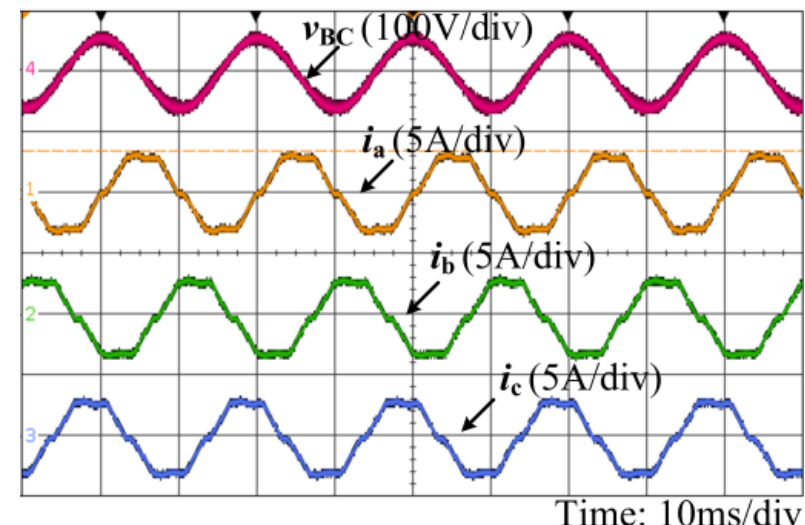

(b)

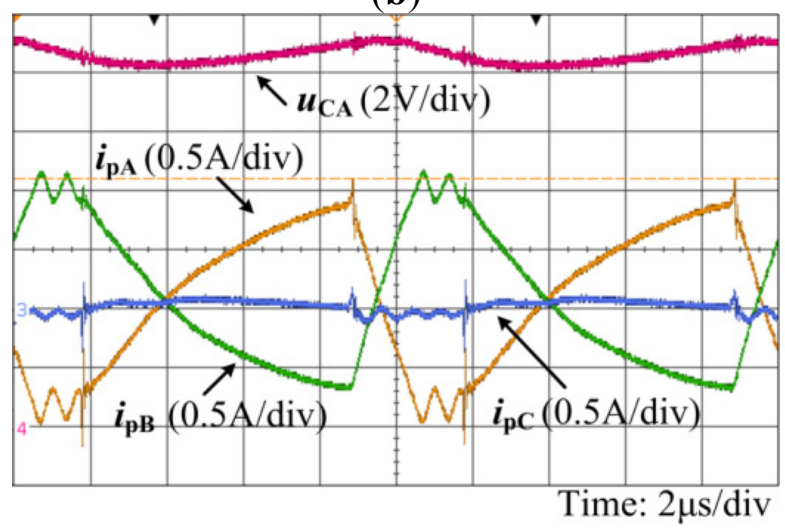

(d)

Figure 20. Experimental results at low input voltage. (a) input line voltage, output voltage and input current; (b) input line voltage and PMSM output currents; (c) gate signal and three phase input current in detail; (d) $u$ CA and secondary currents of flyback cells.

Additionally, as analyzed before, $M_{\mathrm{FM}}$ will reach its peak at around $D=0.6$ if a constant $L_{\mathrm{k}}$ is set. At the same point, the input current distortion caused by flyback cells will be equal to its maximum value as well. Consequently, if the maximum value of $M_{\mathrm{FM}}$ is acceptable, the optimized parameters of the proposed converter can satisfy the design requirements for conversion efficiency. The relevant experiment should be conducted.

In Figure 21, experimental results under the condition that $M_{\mathrm{FM}}$ reaches its peak are presented, where $V_{\text {bus }}$ is $420 \mathrm{~V}, V_{\mathrm{F}}$ is $108.5 \mathrm{~V}$ and $M_{\mathrm{FM}}$ is 0.35 . As it can be seen from Figure $21 \mathrm{a}, \mathrm{b}$, the waveform distortion is obviously larger than that of rated condition. The secondary currents of flyback cells $i_{\mathrm{PA}}$, $i_{\mathrm{PB}}, i_{\mathrm{PC}}$ are almost as twice as that of rated condition, which demonstrates the influence caused by flyback cells have been strengthened. The main parameters of the converter are measured as follows: $D=0.6, V_{\text {in-P }}=34.6 \mathrm{~V} \mathrm{AC}, V_{\mathrm{F}}=108.5 \mathrm{~V}, V_{\text {bus }}=420 \mathrm{~V}, M_{\text {gain }}=12.1, M_{\mathrm{FM}}=0.35, \mathrm{THD}=8.9 \%$, $\mathrm{PF}($ power factor $)=0.99$, Efficiency $\eta=83.1 \%$. 


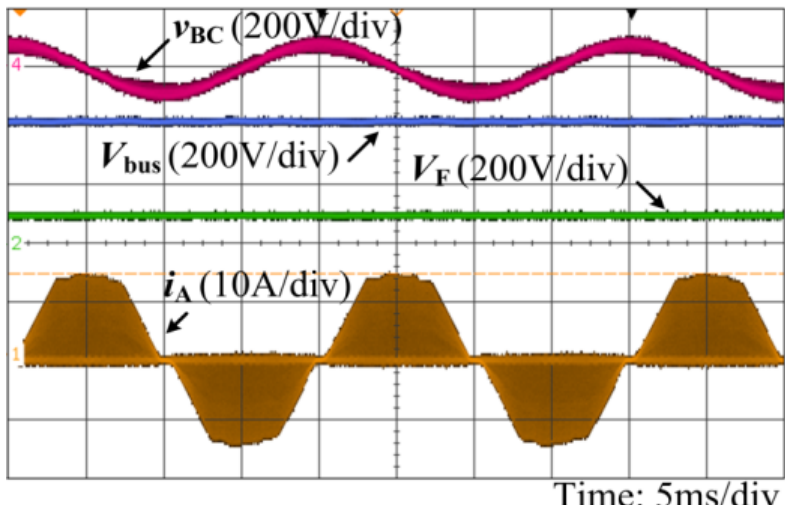

(a)

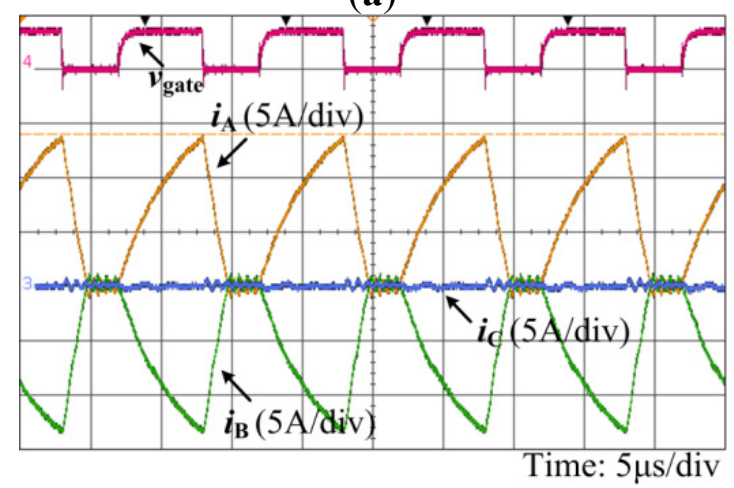

(c)

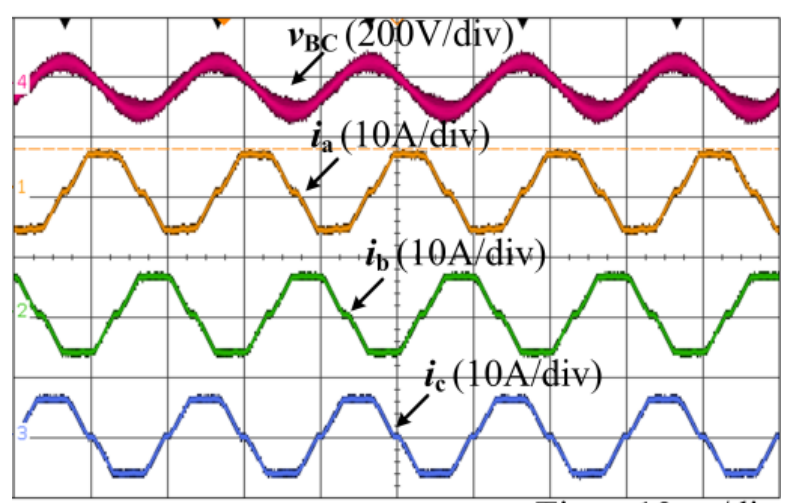

(b)

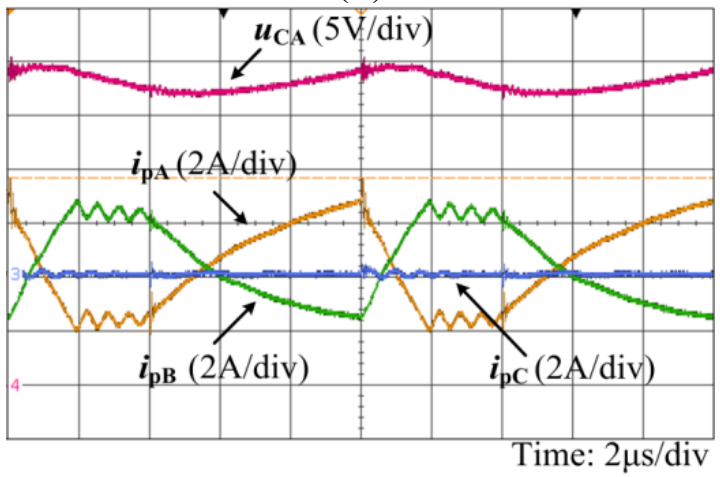

(d)

Figure 21. Experimental results at maximum $M_{\mathrm{FM}}$. (a) input line voltage, output voltage and input current; (b) input line voltage and PMSM output currents; (c) gate signal and three phase input current in detail; (d) $u$ CA and secondary currents of flyback cells.

Finally, the relationships between efficiency/THD and output power are shown in Figure 22a,b. The conversion efficiency increases from $81.9 \%$ to $87.6 \%$ when the output power grows from 100 to $400 \mathrm{~W}$. The efficiency can reach $87.6 \%$ at rated condition. The maximum THD is $8.9 \%$, and at rated condition, THD is equal to $7.4 \%$. The power factor is 0.99 at rated. Thus, in small power level application, the proposed converter can obtain the relatively high conversion efficiency, high power factor and low THD.

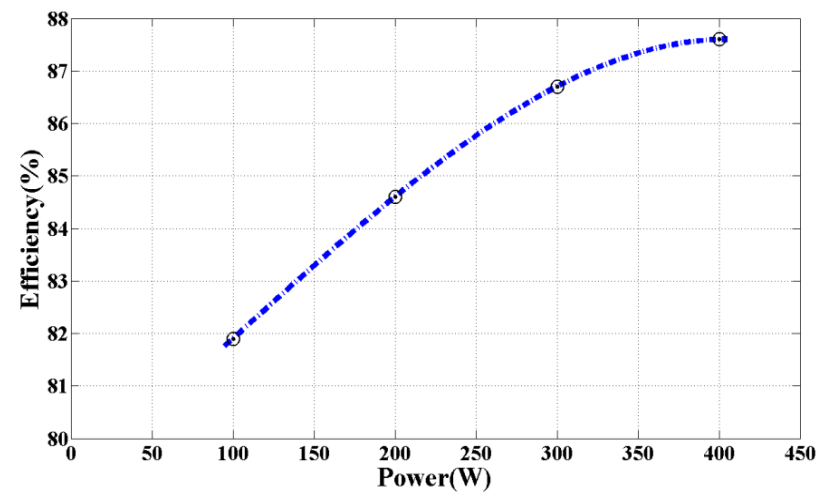

(a)

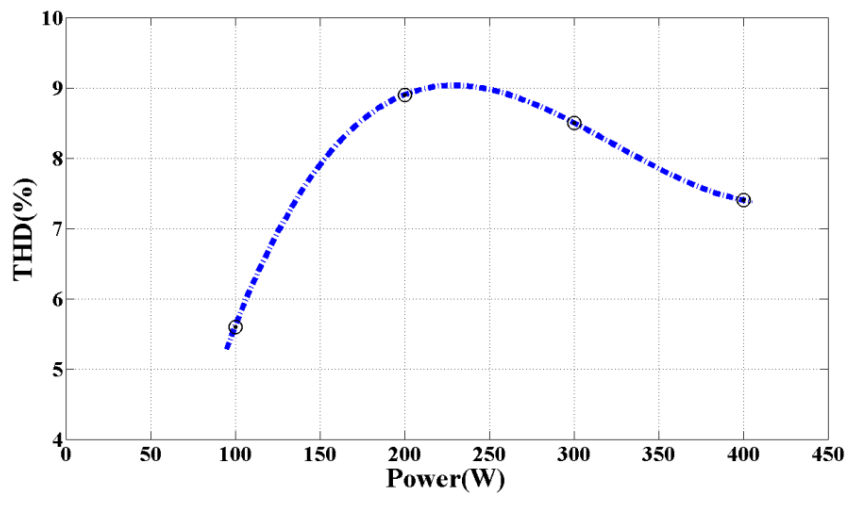

(b)

Figure 22. Relationship between efficiency/THD and output power. (a) measured efficiency; (b) measured THD. 


\section{Conclusions}

A novel three-phase high step-up single-switch flyback converter with switched capacitors has been proposed in this paper. Unlike widely applied large- and medium-scale wind generation, this converter is especially designed for low power (under $1 \mathrm{~kW}$ ) usage, such as building roofs or electricity-lacking areas. It integrates the three-phase single-switch boost circuit and the flyback circuit with switched capacitor cells.

The converter can achieve high voltage gain at low input voltage, and high efficiency, high power factor, low THD at rated input voltage. Additionally, since no electrolytic capacitor is employed, this converter can realize the weak power collection at extremely low input voltage. Finally, a rated $400 \mathrm{~W}$ prototype with efficiency $87.4 \%$ and THD $7.4 \%$ is built and tested to verify the theoretical analysis.

\section{Acknowledgments}

This research was supported by the National Natural Science Foundation of China (Grant: 51307117) and supported by Tianjin Municipal Science and Technology Commission (Grant: 14ZCZDGX00035). The authors would also like to thank the anonymous reviewers for their valuable comments and suggestions to improve the quality of the paper.

\section{Author Contributions}

Yi-Feng Wang, Liang Yang and Cheng-Shan Wang designed the main parts of the study, including the circuit simulation model, topology innovation and simulation development. Wei Li helped in the PSIM circuit model development and simulation. Wei Qie and Shi-Jie Tu were also responsible for writing the paper.

\section{Conflicts of Interest}

The authors declare no conflict of interest.

\section{References}

1. World Wind Energy Half-Year Report 2014; World Wind Energy Association: Bonn, Germany, 2014.

2. Blaabjerg, F.; Liserre, M.; Ma, K. Power electronics converters for wind turbine systems. IEEE Trans. Ind. Appl. 2012, 48, 708-719.

3. Tsai, C.T.; Shen, C.L. A high step-down interleaved buck converter with active-clamp circuits for wind turbines. Energies 2012, 5, 5150-5170.

4. Tsai, C.T.; Shen, C.L.; Su, J.C. A power supply system with ZVS and current-doubler features for hybrid renewable energy conversion. Energies 2013, 6, 4859-4878.

5. Koutroulis, E.; Kalaitzakis, K. Design of a maximum power tracking system for wind-energy-conversion applications. IEEE Trans. Ind. Electron. 2006, 53, 486-494.

6. Satpathy, A.S.; Kishore, N.K.; Kastha, D.; Sahoo, N.C. Control scheme for a stand-alone wind energy conversion system. IEEE Trans. Energy Convers. 2014, 29, 418-425. 
7. Latif, T.; Razzak, M.A. Design of a wind power generation system using permanent magnet synchronous machine along with a boost regulator. In Proceedings of the 3rd International Conference on Developments in Renewable Energy Technology (ICDRET), Dhaka, Bangladesh, 29-31 May 2014; pp. 1-6.

8. Wang, S.; Qi, Z.; Undeland, T. State space averaging modeling and analysis of disturbance injection method of MPPT for small wind turbine generating systems. In Proceedings of the Power and Energy Engineering Conference, Wuhan, China, 27-31 March 2009; pp. 1-5.

9. Wang, H.; Nayar, C.; Su, J.; Ding, M. Control and interfacing of a grid-connected small-scale wind turbine generator. IEEE Trans. Energy Convers. 2011, 26, 428-434.

10. Prasad, A.R.; Ziogas, P.D.; Manias, S. An active power factor correction technique for three-phase diode rectifiers. IEEE Trans. Power. Electron. 1991, 6, 83-92.

11. Wiroj, T.; Hatada, T.; Wada, K.; Akagi, H. Design and performance of a transformerless shunt hybrid filter integrated into a three-phase diode rectifier. IEEE Trans. Power Electron. 2007, 22, 1882-1889.

12. Wu, J.C. AC/DC power conversion interface for self-excited induction generator. IET Renew. Power Gener. 2009, 3, 144-151.

13. Orlando, N.A.; Liserre, M.; Mastromauro, R.A.; Aquila, A.D. A survey of control issues in PMSG-based small wind-turbine systems. IEEE Trans. Ind. Inform. 2013, 9, 1211-1221.

14. Teodorescu, R.; Blaabjerg, F. Flexible control of small wind turbines with grid failure detection operating in stand-alone and grid-connected mode. IEEE Trans. Power. Electron. 2004, 19, 1323-1332.

15. Pena, R.; Clare, J.; Asher, G. Doubly-fed induction generator using back-to-back PWM converters and its applications to variable-speed wind-energy generation. Proc. Inst. Elect. Eng. B 1996, 53, 231-241.

16. Kouro, S.; Malinowski, M.; Gopakumar, K.; Pou, J.; Franquelo, L.G.; Wu, B.; Rodriguez, J.; Pérez, M.A.; Leon, J.I. Recent advances and industrial applications of multilevel converters. IEEE Trans. Ind. Electron. 2010, 57, 2553-2580.

17. Cárdenas, R.; Peña, R.; Tobar, G.; Clare, J.; Wheeler, P.; Asher, G. Stability analysis of a wind energy conversion system based on a doubly fed induction generator fed by a matrix converter. IEEE Trans. Ind. Electron. 2009, 56, 4194-4206.

18. Cárdenas, R.; Peña, R.; Tobar, G.; Clare, J.; Wheeler, P. Analytical and experimental evaluation of a WECS based on a cage induction generator fed by a matrix converter. IEEE Trans. Energy Convers. 2011, 26, 204-215.

19. Cisneros, R.; Mancilla-David, F.; Ortega, R. Passivity-Based control of a grid-connected small-scale windmill with limited control authority. IEEE J. Emerg. Sel. Top. Power Electron. 2013, 1, 247-259.

20. Carranza, O.; Figures, E.; Carcera, G.; Ortega, R.; Velasco, D. Low power wind generation system based on variable speed permanent magnet synchronous generators. In Proceedings of the IEEE International Symposium on Industrial Electronics (ISIE), Gdansk, Poland, 27-30 June 2011; pp. 1063-1068.

21. Yao, K.; Ruan, X.; Zou, C.; Ye, Z. Three-phase single-switch boost power factor correction converter with high input power factor. IET Power Electron. 2012, 5, 1095-1103. 
22. Chen, L.; Soong, W.L.; Pathmanathan, M.; Ertugrul, N. Comparison of AC/DC converters and the principles of a new control strategy in small-scale wind turbine systems. In Proceedings of the 22nd Australasian Universities Power Engineering Conference (AUPEC), Bali, Indonesia, 26-29 September 2012; pp. 1-6.

23. Freddy, F.B.; Hugo, V.B.; Josep, M.B.; Antonio, L.M.; Luis, M.S. Grid-Connected boost inverter for small-wind urban integration: Analysis and design. In Proceedings of the 38th Annual Conference on IEEE Industrial Electronics Society, Montreal, QC, Canada, 25-28 October 2012; pp. 433-439.

24. Zhao, Y.; Li, W.; Deng, Y.; He, X. High step-up boost converter with passive lossless clamp circuit for non-isolated high step-up applications. IET Power Electron. 2011, 4, 851-859.

25. Liang, T.J.; Tseng, K.C. Analysis of integrated boost-flyback step-up converter. IEE Proc. Electr. Power Appl. 2005, 152, 217-225.

26. Liang, T.J.; Chen, S.M.; Yang, L.S.; Chen, J.F.; Adrian, I. A single switch boost-flyback dc-dc converter integrated with switched-capacitor cell. In Proceedings of the IEEE 8th International Conference on Power Electronics and ECCE Asia (ICPE \& ECCE), Jeju, Korea, 30 May-3 June 2011; pp. 2782-2787.

27. Zhao, Q.; Lee, F.C. High-Efficiency, high step-up DC-DC converters. IEEE Trans. Power Electron. 2003, 18, 65-73.

28. Hsieh, Y.P.; Chen, J.F.; Liang, T.J.; Yang, L.S. Novel high step-up DC-DC converter for distributed generation system. IEEE Trans. Ind. Electron. 2013, 60, 1473-1482.

29. Prudente, M.; Pfitscher, L.L.; Emmendoerfer, G.; Romaneli, E.F.; Gules, R. Voltage multiplier cells applied to non-isolated DC-DC converters. IEEE Trans. Power Electron. 2008, 23, 871-887.

30. Law, K.K.; Cheng, K.W.E.; Yeung, T.P.B. Design and analysis of switched-capacitor-based step-up resonant converters. IEEE Trans. Circuits Syst. I Regul. Papers 2005, 52, 943-948.

31. Hsieh, Y.P.; Chen, J.F.; Liang, T.J.; Yang, L.S. Novel high step-up DC-DC converter with coupled-inductor and switched-capacitor techniques. IEEE Trans. Ind. Electron. 2012, 59, 998-1007.

32. Chung, H.S.H. Design and analysis of a switched-capacitor-based step-up DC/DC converter with continuous input current. IEEE Trans. Circuits Syst. I Fund. Theory Appl. 1999, 46, 772-730.

33. Hsieh, Y.P.; Chen, J.F.; Liang, T.J.; Yang, L.S. Novel high step-up DC-DC converter with coupled-inductor and switched-capacitor techniques for a sustainable energy system. IEEE Trans. Power Electron. 2011, 26, 3481-3490.

34. Mei, Q.; Shan, M.; Liu, L.; Guerrero, J.M. A novel improved variable step-size incremental-resistance MPPT method for PV systems. IEEE Trans. Ind. Electron. 2011, 58, 2427-2434.

35. Zhang, H.; Ji, H.; Ren, J.; Shan, L.; Gao, Y. Research on MPPT control and implementation method for photovoltaic generation system and its simulation. In Proceedings of the IEEE 6th International Power Electronics and Motion Control Conference, Wuhan, China, 17-20 May 2009; pp. 2108-2112.

(C) 2015 by the authors; licensee MDPI, Basel, Switzerland. This article is an open access article distributed under the terms and conditions of the Creative Commons Attribution license (http://creativecommons.org/licenses/by/4.0/). 